\title{
Separating mixtures of aerosol types in airborne High Spectral Resolution Lidar data
}

\author{
S. P. Burton, M. A. Vaughan, R. A. Ferrare, and C. A. Hostetler \\ NASA Langley Research Center, MS 475, Hampton, VA, 23681, USA \\ Correspondence to: S. P. Burton (sharon.p.burton@nasa.gov)
}

Received: 17 August 2013 - Published in Atmos. Meas. Tech. Discuss.: 6 September 2013

Revised: 13 December 2013 - Accepted: 20 December 2013 - Published: 7 February 2014

\begin{abstract}
Knowledge of aerosol type is important for determining the magnitude and assessing the consequences of aerosol radiative forcing, and can provide useful information for source attribution studies. However, atmospheric aerosol is frequently not a single pure type, but instead occurs as a mixture of types, and this mixing affects the optical and radiative properties of the aerosol. This paper extends the work of earlier researchers by using the aerosol intensive parameters measured by the NASA Langley Research Center airborne High Spectral Resolution Lidar (HSRL-1) to develop a comprehensive and unified set of rules for characterizing the external mixing of several key aerosol intensive parameters: extinction-to-backscatter ratio (i.e., lidar ratio), backscatter color ratio, and depolarization ratio. We present the mixing rules in a particularly simple form that leads easily to mixing rules for the covariance matrices that describe aerosol distributions, rather than just single values of measured parameters. These rules can be applied to infer mixing ratios from the lidar-observed aerosol parameters, even for cases without significant depolarization. We demonstrate our technique with measurement curtains from three HSRL-1 flights which exhibit mixing between two aerosol types, urban pollution plus dust, marine plus dust, and smoke plus marine. For these cases, we infer a time-height cross-section of extinction mixing ratio along the flight track, and partition aerosol extinction into portions attributed to the two pure types.
\end{abstract}

\section{Introduction}

Atmospheric aerosols play an important role in climate change and solar energy availability and affect air quality and human health, but there are still significant uncertainties in our knowledge of the radiative effects of aerosol (IPCC, 2007). The vertical distribution of aerosol is particularly important, since aerosol lifetime and climate response depend on altitude (Hansen et al., 1997). Uniquely among remote sensing measurement techniques, lidar provides vertically resolved measurements of the distribution of aerosol properties within the atmospheric column. At the same time, the determination of aerosol radiative forcing and source attribution also requires knowledge of aerosol type. Depending on the sophistication of the lidar instrument, one or more aerosol intensive parameters can be measured. Intensive parameters are quantities that vary only with aerosol type and not amount and which can therefore be used for aerosol classification (Burton et al., 2012; Groß et al., 2013b). For the NASA Langley Research Center (LaRC) airborne High Spectral Resolution Lidar (HSRL-1) (Hair et al., 2008), these parameters include the depolarization ratio at 532 and $1064 \mathrm{~nm}$, aerosol extinction to backscatter ratio (lidar ratio) at $532 \mathrm{~nm}$, and the spectral ratio of aerosol backscatter (i.e., backscatter color ratio).

Observed aerosol layers are frequently mixtures of multiple types (e.g., Lesins et al., 2002; Tesche et al., 2011; David et al., 2013). For passive instruments, which observe full columns rather than vertically resolved profiles, the measurements reflect an effective mix of aerosols throughout the column. The assumption of a single aerosol type throughout the column is also frequently required in retrievals of aerosol extinction from elastic backscatter lidar (even though the backscatter measurements are vertically resolved) (Fernald, 1984). Standard retrievals for the Cloud-Aerosol Lidar with Orthogonal Polarization (CALIOP) lidar instrument on the Cloud-Aerosol Lidar and Infrared Pathfinder Satellite Observations (CALIPSO) satellite do not make this assumption; 
however, they do require significant averaging that can result in layers that include multiple different aerosol types. In those cases, the effective lidar ratio and other properties depend on multiple types, complicating the retrieval (Burton et al., 2013). Even in very highly resolved measurements, aerosols are often present in a mixed state (Tesche et al., 2009; Petzold et al., 2011). Mixing between aerosol types can be either external or internal. In external mixing, the aerosol particles are physically separated and individually pure. Composite particles formed by, for example, coagulation or aqueous reactions are considered internal mixtures (Lesins et al., 2002). We focus on external mixtures in this paper.

Aerosol classification schemes for lidar data (Burton et al., 2012; Groß et al., 2013b; Weinzierl et al., 2011; Omar et al., 2009) focus mainly on pure aerosol types, but also include some mixtures, for example Polluted Dust in the CALIPSO aerosol classification (Omar et al., 2009) and Polluted Maritime and Dusty Mix in the NASA HSRL-1 classification (Burton et al., 2012). Groß et al. (2013b) also address mixtures, by including mixing lines to indicate regions in the multi-dimensional measurement space representing mixtures between two types, either Saharan dust and marine aerosol or Saharan dust and biomass-burning aerosol. These mixing line equations build on a heritage (including Groß et al., 2011; Gasteiger et al., 2011; Tesche et al., 2009) that dates back at least a decade. Léon et al. (2003) and Kaufman et al. (2003) used equations for the inverse lidar ratio and backscatter Ångstrøm exponent for a mixture of two modeled aerosol modes. Sugimoto et al. (2003) examined mixtures of dust and non-dust aerosol and derived equations linking the depolarization with the partitioning of backscatter and, in later work, the backscatter-related Angstrøm exponent (Sugimoto and Lee, 2006). While not explicitly providing equations for aerosol intensive properties of mixtures, Nishizawa et al. (2011) do an extinction retrieval similar to that of Léon et al. (2003) but use both the depolarization ratio and spectral relationship of the measured backscatter to choose between three specific aerosol models; they present results as partitions of aerosol extinction. In this paper, we infer mixing ratios and extinction partitions for various cases of mixing, including a non-dust case where we cannot rely on variation in the depolarization ratio to achieve the separation. We also expand on the equations of Léon et al. (2003) and Sugimoto and Lee (2006) by showing that, with a fortuitous choice of variables, the mixing equations can all be recast in the form of linear combinations. This more convenient form then leads easily to a representation of the full variancecovariance matrices for mixtures of multivariate normal distributions as well.

The classification algorithms used by Groß et al. (2013b) and Weinzierl et al. (2011) for German Aerospace Center (DLR) Falcon HSRL measurements use a simple set of thresholds in each measurement dimension to classify aerosols. However, multivariate normal distributions provide a more complete picture of aerosol properties, and can be more useful for some applications (e.g., Russell et al., 2014). Multivariate normal distributions of aerosol types were calculated from the NASA Langley HSRL-1 (Burton et al., 2012) and are an important part of the aerosol classification methodology in use for that instrument. This article builds on the work of Burton et al. (2012) and shows mixtures of aerosol types in the framework of multivariate normal distributions using measurements from the NASA Langley airborne HSRL-1.

Following a brief instrument description in Sect. 2, Sect. 3 presents a derivation of the linear mixing equations for aerosol intensive parameters, expanding on the work in these earlier papers (especially Léon et al., 2003; Sugimoto and Lee, 2006; Burton et al., 2012). In Sect. 4, we extend the equations to include not just the mean values but also the full covariance matrix for a mixture of two or more puretype multivariate normal distributions. In the second half of this paper, in Sects. 5-7, we will show three case studies of external mixtures observed by the NASA Langley airborne HSRL-1, which satisfy the derived relationships. We also estimate mixing ratios for our case studies and show the apportionment of aerosol extinction to the two constituent types.

\section{Instrument description}

HSRL-1 (Hair et al., 2008) is the first airborne high spectral resolution lidar instrument built and operated by NASA Langley Research Center. Between March 2006 and October 2012, HSRL-1 flew more than $1200 \mathrm{~h}$ during its 357 science flights on the NASA King Air B200 on 20 field campaigns across North America. The HSRL technique independently retrieves aerosol and tenuous cloud extinction and backscatter (Grund and Eloranta, 1991) without a priori information on aerosol type or extinction-to-backscatter ratio, as is required for standard elastic backscatter lidar retrievals. The NASA HSRL-1 employs the HSRL technique at $532 \mathrm{~nm}$ and the standard backscatter technique at $1064 \mathrm{~nm}$. It also measures depolarization ratio at both wavelengths. HSRL-1 is well calibrated and has been extensively validated using in situ and remote sensing measurements; the HSRL-1 aerosol optical thickness (AOT) product was shown to be within $6 \%$ of measurements from well-established sensors (Rogers et al., 2009). The measurement techniques and calibration procedures enable direct and unambiguous retrieval of loading-invariant aerosol intensive properties in addition to loading-dependent extensive properties such as AOT. The intensive properties provided by HSRL-1 are the $532 \mathrm{~nm} \mathrm{li-}$ dar ratio, the aerosol depolarization ratios at both 532 and $1064 \mathrm{~nm}$, and the backscatter color ratio (i.e., the ratio of aerosol backscatter coefficients at the two wavelengths; the $1064 \mathrm{~nm}$ backscatter depends on a nominal lidar ratio, but the systematic error this assumption produces does not greatly affect the ratio used in aerosol classification, due to limited 
sensitivity of backscatter to the lidar ratio assumption at $1064 \mathrm{~nm}$ (Burton et al., 2012)).

Burton et al. (2012) describe how the intensive parameters provide information about the aerosol physical properties and are combined to infer aerosol type. In that study, a two-part classification is performed. In the first part, a set of thirty HSRL-1 observation samples are identified where the aerosol type is known (using external information including back-trajectory analysis, in situ observations, visual identification of plumes, etc.) and from these a set of eight aerosoltype models are created in the form of multi-normal covariance matrices. In the second part of the classification, every observation from the entire comprehensive HSRL-1 data set of 20 field campaigns is classified by choosing the best fitting model out of the eight multi-normal distributions using a generalized 4-dimensional distance metric, the Mahalanobis distance (Mahalanobis, 1936). The results of this classification are now considered a standard data product for the Langley HSRL-1 and HSRL-2 instruments. In Sects. 5-7 of this study, we show examples of HSRL-1 observations that illustrate mixing between two pure aerosol types. The pure type samples are chosen with the aid of the standard classification algorithm, but multi-normal covariance matrices are created specifically for these samples as discussed below (that is, we do not use generalized "pure type" models).

\section{Mixing relationships}

Analytically derived lidar observables for mixtures are discussed by Kaufman et al. (2003) and Léon et al. (2003), who derive backscatter-to-extinction ratio and a backscatterrelated pseudo-Ångstrøm exponent for a mixture of a fine and a coarse aerosol mode using Moderate Resolution Imaging Spectroradiometer (MODIS) aerosol models. Their starting point is a simple partition of extinction, $\alpha$, into fine and coarse modes with the fine-mode fraction defined in terms of aerosol extinction.

$f \equiv \frac{\alpha_{\mathrm{s}}}{\alpha_{\mathrm{s}}+\alpha_{1}}$.

Here, subscripts "s" and "l" indicate small and large mode. We are interested in the lidar ratio, or extinction-tobackscatter ratio, the inverse of the quantity used by Léon et al. (2003). The pseudo-Ångstrøm exponent they use is likewise related to the backscatter color ratio we use, but not identical. Also, we wish to mix two arbitrary aerosol types, which we will call a and b, not single modes. Therefore, we start our derivation from a slightly different point, with the goal of producing mixing equations in a very simple form. Nevertheless the mixing relations given here are consistent with those given by earlier authors, and we will show how to convert between them later in this section (Eq. 20).
We start with a mixing ratio (partition) defined in terms of aerosol backscatter

$p \equiv \frac{\beta_{\mathrm{a}}}{\beta_{\mathrm{a}}+\beta_{\mathrm{b}}}$,

where $\beta$ denotes aerosol backscatter coefficient, and subscripts "a" and "b" denote the contributions from two types. First, the aerosol backscatter component of each constituent type can be written in terms of the partition and the backscatter of the mixture:

$\beta_{\mathrm{a}}=p \beta$

$\beta_{\mathrm{b}}=(1-p) \beta$.

Then, to represent the aerosol extinction, $\alpha$, for the constituent types, we apply the aerosol extinction-to-backscatter ratio, or lidar ratio, $S$.

$\alpha_{\mathrm{a}}=S_{\mathrm{a}} \beta_{\mathrm{a}}=S_{\mathrm{a}} p \beta$

$\alpha_{\mathrm{b}}=S_{\mathrm{b}} \beta_{\mathrm{b}}=S_{\mathrm{b}}(1-p) \beta$.

We note that the aerosol lidar ratio is typically represented as $S_{\text {a }}$ with a subscript "a" for "aerosol". In this work, however, we drop this customary subscript to avoid confusing it with the subscripts "a" and "b" indicating specific aerosol types. All lidar ratios, depolarization ratios, and backscatter and extinction coefficients in this paper should be understood to represent the aerosol component only, with the molecular component already removed.

With the definitions of aerosol extinction and backscatter for the two types given in Eqs. (3)-(6), we can proceed to deriving the lidar ratio of the mixture. The lidar ratio is the ratio of aerosol extinction to aerosol backscatter coefficient.

$S=\frac{\alpha}{\beta}$.

Inserting Eqs. (5) and (6) in the numerator,

$=\frac{\left[S_{\mathrm{a}} p+S_{\mathrm{b}}(1-p)\right] \beta}{\beta}$.

Cancelling terms in the numerator and denominator leaves a simple expression for the lidar ratio of the mixture in terms of a linear combination of the lidar ratio of each of the two constituent types.

$S=S_{\mathrm{a}} p+S_{\mathrm{b}}(1-p)$.

This relationship is true at any wavelength, but both the lidar ratios and the coefficient $p$ are wavelength dependent. We must therefore derive the wavelength dependence of the mixing coefficient, $p$. Accordingly, we will introduce a superscript $\lambda$ to indicate the wavelength dependence of the partition and other quantities and write Eq. (2) more explicitly for the $1064 \mathrm{~nm}$ channel.

$p_{1064}=\frac{\beta_{\mathrm{a}}^{1064}}{\beta_{\mathrm{a}}^{1064}+\beta_{\mathrm{b}}^{1064}}$. 
To get the relationships between channels, we need the backscatter color ratio

$\chi=\frac{\beta^{532}}{\beta^{1064}}$.

The color ratios for the two pure types will be indicated by $\chi_{\mathrm{a}}$ and $\chi_{\mathrm{b}}$. The backscatter partition at $532 \mathrm{~nm}$ is derived following similar steps.

$$
\begin{aligned}
p_{532} & =\frac{\beta_{\mathrm{a}}^{532}}{\beta_{\mathrm{a}}^{532}+\beta_{\mathrm{b}}^{532}} \\
& =\frac{\chi_{\mathrm{a}} \beta_{\mathrm{a}}^{1064}}{\chi_{\mathrm{a}} \beta_{\mathrm{a}}^{1064}+\chi_{\mathrm{b}} \beta_{\mathrm{b}}^{1064}} .
\end{aligned}
$$

Combining with Eqs. (3) and (4) and cancelling out the total aerosol backscatter in the numerator and denominator, we are left with the following equation, which gives the wavelength dependence of the backscatter partition. As long as the partition is known at one wavelength, along with color ratio values for the two pure types, the partition at other wavelengths can be obtained.

$$
p_{532}=\frac{\chi_{\mathrm{a}} p_{1064}}{\chi_{\mathrm{a}} p_{1064}+\chi_{\mathrm{b}}\left(1-p_{1064}\right)} .
$$

We can write the equation for the lidar ratio at $532 \mathrm{~nm}$ as a linear combination of the $532 \mathrm{~nm}$ lidar ratios of each pure type like this:

$S^{532}=S_{\mathrm{a}}^{532} p_{532}+S_{\mathrm{b}}^{532}\left(1-p_{532}\right)$

or like this:

$S^{532}=\frac{S_{\mathrm{a}}^{532} \chi_{\mathrm{a}} p_{1064}+S_{\mathrm{b}}^{532} \chi_{\mathrm{b}}\left(1-p_{1064}\right)}{\chi_{\mathrm{a}} p_{1064}+\chi_{\mathrm{b}}\left(1-p_{1064}\right)}$.

The backscatter color ratio itself is an aerosol intensive parameter that is used in aerosol classification. Accordingly, we derive the mixing coefficient of the backscatter color ratio itself.

$$
\chi=\frac{\chi_{\mathrm{a}} \beta_{\mathrm{a}}^{1064}+\chi_{\mathrm{b}} \beta_{\mathrm{b}}^{1064}}{\beta_{\mathrm{a}}^{1064}+\beta_{\mathrm{b}}^{1064}}
$$

$\chi=\frac{\left[\chi_{\mathrm{a}} p_{1064}+\chi_{\mathrm{b}}\left(1-p_{1064}\right)\right] \beta^{1064}}{\beta^{1064}}$

$\chi=\chi_{\mathrm{a}} p_{1064}+\chi_{\mathrm{b}}\left(1-p_{1064}\right)$.

So this also mixes linearly. That is, the form of the equation is the same as Eq. (9) and furthermore the mixing coefficient is the same as for the lidar ratio at $1064 \mathrm{~nm}$.

A similar derivation yields the relationship between the backscatter partition $p_{\lambda}$ at any wavelength and the partition of extinction, $f_{\lambda}$, that was defined in Eq. (1).

$$
f_{\lambda}=\frac{S_{\mathrm{a}}^{\lambda} p_{\lambda}}{S_{\mathrm{a}}^{\lambda} p_{\lambda}+S_{\mathrm{b}}^{\lambda}\left(1-p_{\lambda}\right)} .
$$

The final intensive parameter that we use for aerosol classification is the aerosol depolarization ratio. Following the same logic as Sugimoto and Lee (2006), it is possible to derive the aerosol depolarization ratio of a mixture. Multiple definitions of depolarization ratio are in use (Cairo et al., 1999; Gimmestad, 2008), and we must be specific. We consider only the depolarization due to aerosols, and, using the same notation as Sugimoto and Lee (2006), we use the symbol $\delta$ for the ratio of the aerosol backscatter coefficient measured in the perpendicular channel to that measured in the parallel channel,

$\delta=\frac{\beta_{\perp}}{\beta_{\|}}$

and the symbol $\delta^{\prime}$ for the ratio of perpendicular to total aerosol backscatter.

$\delta^{\prime}=\frac{\beta_{\perp}}{\beta_{\|}+\beta_{\perp}}$

$\delta^{\prime}=\frac{\delta}{1+\delta}$.

Note that the second half of Sugimoto and Lee's (2006) Eq. (3) relating the two depolarization parameters includes a typographical error. It should be this:

$\delta=\frac{\delta^{\prime}}{1-\delta^{\prime}}$

Aerosol depolarization measurements from lidar are usually reported as defined by Eq. (21) . This includes archived aerosol depolarization ratio measurements from the NASA airborne HSRL-1 used in this study and by Burton et al. (2012). However, for the mixing equations in this study, we will use $\delta^{\prime}$ from Eq. (22) because this is the quantity that mixes linearly. To distinguish between them more conveniently, we will use the term "aerosol depolarization potential" for the quantity $\delta^{\prime}$ and the term "aerosol depolarization ratio" for the more familiar quantity, $\delta$. The term "depolarization potential" is inspired by Gimmestad (2008) who describes it as "a measure of the propensity of the scattering medium to depolarize the incident polarization."

Sugimoto and Lee (2006) use the backscatter mixing ratio, which they call $X$, and we call $p_{532}$. Without assuming that one type is totally non-depolarizing as they do, we can write a more general form of their Eq. (6) for two types. Sugimoto and Lee's equation relates the depolarization ratio, $\delta$, of a mixture to the depolarization potential, $\delta^{\prime}$, of the two types. Here we combine their equation and Eq. (24) to write the relationship entirely in terms of $\delta^{\prime}$. With some algebra, this makes it a linear equation and therefore more useful for our later development in Sect. 4.

$\frac{\delta^{\prime}{ }_{532}^{\operatorname{mix}}}{1-\delta^{\prime}{ }_{532}}=\frac{\delta^{\prime}{ }_{\mathrm{a}} p_{532}+\delta^{\prime}{ }_{\mathrm{b}}\left(1-p_{532}\right)}{\left(1-\delta^{\prime}{ }_{\mathrm{a}}\right) p_{532}+\left(1-\delta^{\prime}{ }_{\mathrm{b}}\right)\left(1-p_{532}\right)}$. 
Invert and add 1 to both sides:

$$
\begin{aligned}
\frac{1}{\delta^{\prime \prime}{ }_{532}} & =\frac{\left(1-\delta^{\prime}{ }_{\mathrm{a}}\right) p_{532}+\left(1-\delta^{\prime} \mathrm{b}\right)\left(1-p_{532}\right)}{\delta^{\prime}{ }_{\mathrm{a}} p_{532}+\delta^{\prime}{ }_{\mathrm{b}}\left(1-p_{532}\right)} \\
& +\frac{\delta^{\prime}{ }_{\mathrm{a}} p_{532}+\delta^{\prime}{ }_{\mathrm{b}}\left(1-p_{532}\right)}{\delta^{\prime}{ }_{\mathrm{a}} p_{532}+\delta^{\prime}{ }_{\mathrm{b}}\left(1-p_{532}\right)} .
\end{aligned}
$$

Canceling terms in the numerator and inverting again yields

$\delta_{532}^{\prime \operatorname{mix}}=\delta^{\prime}{ }_{\mathrm{a}} p_{532}+\delta^{\prime}{ }_{\mathrm{b}}\left(1-p_{532}\right)$.

Not only is this in the convenient form of a linear combination, but the linear coefficient is the same as the $532 \mathrm{~nm}$ backscatter mixing ratio found in Eq. (15).

\section{Multivariate normal distributions for mixture types}

The previous section provides mixing rules for the mean values of lidar intensive parameters. However, as discussed in the introduction, for some applications it is useful to examine not just mean values, but also to estimate model distributions for the mixtures. Burton et al. (2012) use multivariate normal distributions for various aerosol types, including both pure types and some mixtures, which were based on HSRL measurements of various types. However, the mixtures included in this scheme were based empirically on specific mixture cases that were straightforward to identify in HSRL-1 observations. Here, we analytically calculate the multivariate normal distributions of a mixture, given covariance matrices describing distributions for two pure types. Recall that the set of normal distributions is closed under linear transformations. Therefore, the equations in Sect. 3 showing lidarobserved aerosol intensive parameters in the form of linear combinations are in a particularly convenient form. Following Burton et al. (2012) and earlier authors (Cattrall et al., 2005), we assume that the lidar measurements for pure types can be approximated by multivariate normal distributions; in that case, the linear equations imply that a mixture of two pure types with a specific mixing ratio can also be approximated as a multivariate normal distribution.

Specifically, given that an optical measurement of depolarization potential, lidar ratio, or color ratio - written generically by $x_{\text {mix }}-$ can be represented as a linear combination of two pure types as given in Sect. 3,

$x_{\text {mix }}=p x_{\mathrm{a}}+(1-p) x_{\mathrm{b}}$

then we define measurement vectors $\boldsymbol{A}$ and $\boldsymbol{B}$ comprising those three quantities for the two pure types, "a" and "b".

$$
\boldsymbol{A}=\left(\begin{array}{c}
\delta_{\mathrm{a}}^{\prime 532} \\
\mathrm{~S}_{\mathrm{a}}^{532} \\
\chi_{\mathrm{a}}
\end{array}\right) \quad \boldsymbol{B}=\left(\begin{array}{c}
\delta_{\mathrm{b}}^{\prime 532} \\
\mathrm{~S}_{\mathrm{b}}^{532} \\
\chi_{\mathrm{b}}
\end{array}\right) .
$$

The vector $\boldsymbol{X}$ that describes the mixture is given by the vector equation

$\boldsymbol{X}=\mathbf{P} \boldsymbol{A}+(\mathbf{I}-\mathbf{P}) \boldsymbol{B}$,

where $\mathbf{I}$ is the identity matrix and $\mathbf{P}$ is a diagonal matrix composed of the linear coefficient of mixing for each measurement dimension.

$\mathbf{P}=\left(\begin{array}{ccc}\mathrm{p}_{1} & 0 & 0 \\ 0 & \mathrm{p}_{2} & 0 \\ 0 & 0 & \mathrm{p}_{3}\end{array}\right)=$
$\left(\begin{array}{ccc}\frac{\chi_{\mathrm{a}} p_{1064}}{\chi_{\mathrm{a}} p_{1064}+\chi_{\mathrm{b}}\left(1-p_{1064)}\right)} & 0 & 0 \\ 0 & \frac{\chi_{\mathrm{a}} p_{1064}}{\chi_{\mathrm{a}} p_{1064}+\chi_{\mathrm{b}}\left(1-p_{1064}\right)} & 0 \\ 0 & 0 & p_{1064}\end{array}\right)$.

Equation (30) is just a restatement of Eqs. (16), (19) and (27) in vector form. Assuming the state vectors $\boldsymbol{X}, \boldsymbol{A}$ and $\boldsymbol{B}$ are multi-normally distributed with distributions described by covariance matrices $\Sigma_{X}, \Sigma_{A}$ and $\Sigma_{B}$ then, the covariance matrix for the mixing state $\boldsymbol{X}$ is given as follows (Parois and Lutz, 2011):

$\Sigma_{X}=\mathbf{P} \Sigma_{A} \mathbf{P}^{\mathrm{t}}+(\mathbf{I}-\mathbf{P}) \Sigma_{B}(\mathbf{I}-\mathbf{P})^{\mathrm{t}}$,

where superscript $t$ indicates the transpose operation. Recall that the diagonal elements of the covariance matrix are the variances, while the off-diagonal elements are the covariance terms:

$\Sigma=\left(\begin{array}{ccc}\sigma_{1}^{2} & \rho_{12} \sigma_{1} \sigma_{2} & \rho_{13} \sigma_{1} \sigma_{3} \\ \rho_{12} \sigma_{1} \sigma_{2} & \sigma_{2}^{2} & \rho_{23} \sigma_{2} \sigma_{3} \\ \rho_{13} \sigma_{1} \sigma_{3} & \rho_{23} \sigma_{2} \sigma_{3} & \sigma_{3}^{2}\end{array}\right)$,

where $\sigma_{i}$ indicates the standard deviation of $x_{i}$ and $\rho_{i j}$ is Pearson's correlation coefficient describing the correlation between $x_{i}$ and $x_{j}$.

Writing out the diagonal terms of Eq. (32) produces the familiar propagation of errors for a linear combination (e.g., Bevington and Robinson, 1992).

$\sigma_{X i}^{2}=p_{i}^{2} \sigma_{A i}^{2}+\left(1-p_{i}\right)^{2} \sigma_{B i}^{2}$ for $i=\delta_{532}^{\prime}, S_{532}, \chi$.

Equation (32) can be illustrated by simulation, as shown in Fig. 1. Here two covariance matrices are arbitrarily selected to represent pure types. Points randomly selected from these distributions are shown in blue and purple. Blue and purple ellipses show the two-sigma contours of the covariance matrices for the pure types (when representing covariance matrices as ellipses, the major and minor axes are given by the square root of the eigenvalues while the directions are determined by the eigenvectors (Rodgers, 2000)). A specific mixture of the two pure types is calculated numerically by mixing the blue and purple points using three different linear coefficients of mixing for the three dimensions, and these points are shown in orange. The coefficients are $(0.6,0.2$, 

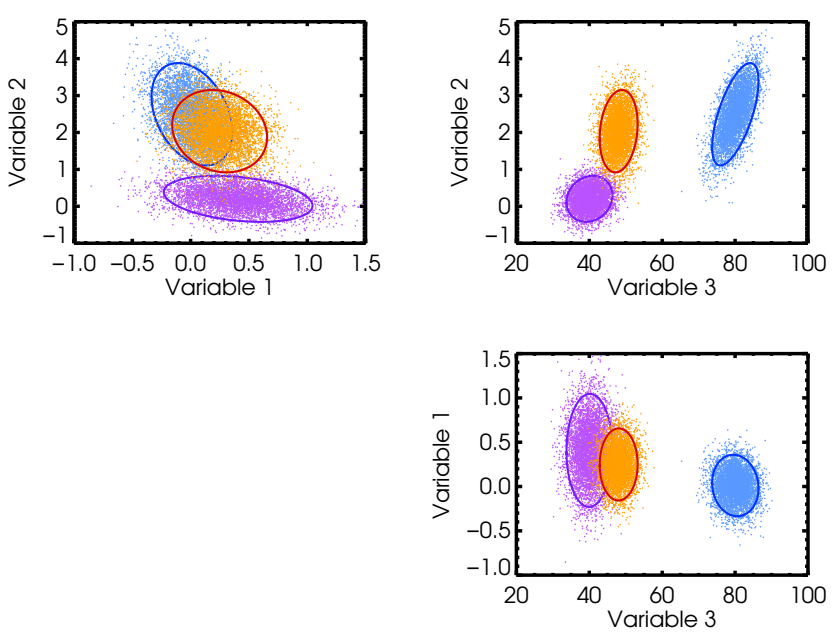

Fig. 1. Illustrates a simulation of mixing in three "measurement" dimensions (Variable 1, Variable 2 and Variable 3) which are shown as 2-D projections in the three panels. Blue and purple indicate two pure types, which are modeled as multivariate normal distributions. The blue and purple points are randomly selected from defined multivariate normal distributions, and the blue and purple ellipses are representations of the two-sigma surfaces of the covariance matrices for these distributions. The orange points are constructed numerically as linear combinations of points from the purple and blue distributions, using a constant mixing coefficient vector, $(0.6,0.2$, 0.8 ). The red ellipses are the $2-\mathrm{D}$ projections of the covariance matrix calculated analytically using Eqs. (30) and (32). The correspondence between the red ellipses, calculated analytically, and the orange points, calculated numerically, is therefore a demonstration of the correctness of Eq. (32).

0.8 ). That is, Variable 1 is calculated as $60 \%$ purple plus $40 \%$ blue, Variable 2 is $20 \%$ purple plus $80 \%$ blue, and Variable 3 is $80 \%$ purple plus $20 \%$ blue. Equation (32) is then used to calculate the covariance matrix of the mixture points, which is represented as a red ellipse in each projection. Since the orange points are calculated numerically and the red ellipses are calculated analytically, and they agree, this simulation provides a demonstration that the form of the equation is correct.

The mixture equations given here can easily be extended to three or more types. For three types, A, B, and C, Eq. (30) becomes

$\boldsymbol{X}=\mathbf{P}_{\mathrm{A}} \boldsymbol{A}+\mathbf{P}_{\mathrm{B}} \boldsymbol{B}+\left(\mathbf{I}-\mathbf{P}_{\mathrm{A}}-\mathbf{P}_{\mathrm{B}}\right) \boldsymbol{C}$,

where $\mathbf{P}_{\mathrm{A}}$ and $\mathbf{P}_{\mathrm{B}}$ represent the vector mixing coefficients for type A and B, respectively. Expanded for each lidar observable as in Eq. (31),

$\mathbf{P}_{\mathrm{A}}=\left(\begin{array}{ccc}p_{1}^{\mathrm{a}} & 0 & 0 \\ 0 & p_{2}^{\mathrm{a}} & 0 \\ 0 & 0 & p_{3}^{\mathrm{a}}\end{array}\right)$ $p_{1}^{\mathrm{a}}=p_{2}^{\mathrm{a}}=\frac{\chi_{\mathrm{a}} p_{1064}^{\mathrm{a}}}{\chi_{\mathrm{a}} p_{1064}^{\mathrm{a}}+\chi_{\mathrm{b}} p_{1064}^{\mathrm{b}}+\chi_{\mathrm{c}}\left(1-p_{1064}^{\mathrm{a}}-p_{1064}^{\mathrm{b}}\right)}$

$p_{3}^{\mathrm{a}}=p_{1064}^{\mathrm{a}}$

and

$\mathbf{P}_{\mathrm{B}}=\left(\begin{array}{ccc}p_{1}^{\mathrm{b}} & 0 & 0 \\ 0 & p_{2}^{\mathrm{b}} & 0 \\ 0 & 0 & p_{3}^{\mathrm{b}}\end{array}\right)$

$p_{1}^{\mathrm{b}}=p_{2}^{\mathrm{b}}=\frac{\chi_{\mathrm{b}} p_{1064}^{\mathrm{b}}}{\chi_{\mathrm{a}} p_{1064}^{\mathrm{a}}+\chi_{\mathrm{b}} p_{1064}^{\mathrm{b}}+\chi_{\mathrm{c}}\left(1-p_{1064}^{\mathrm{a}}-p_{1064}^{\mathrm{b}}\right)}$

$p_{3}^{\mathrm{b}}=p_{1064}^{\mathrm{b}}$.

The covariance matrix for a mixture of three types is given by

$$
\begin{aligned}
\Sigma_{X} & =\mathbf{P}_{\mathbf{A}} \Sigma_{\mathrm{A}} \mathbf{P}_{\mathbf{A}}{ }^{\mathrm{t}}+\mathbf{P}_{\mathbf{B}} \Sigma_{\mathrm{B}} \mathbf{P}_{\mathbf{B}}{ }^{\mathrm{t}} \\
& +\left(\mathbf{I}-\mathbf{P}_{\mathbf{A}}-\mathbf{P}_{\mathbf{B}}\right) \Sigma_{C}\left(\mathbf{I}-\mathbf{P}_{\mathbf{A}}-\mathbf{P}_{\mathbf{B}}\right)^{\mathrm{t}} .
\end{aligned}
$$

\section{HSRL-1 observations of dust and pollution mixtures during MILAGRO}

HSRL-1 data from the MILAGRO (Megacity Initiative: Local and Global Research Observations) campaign provide a further illustration of Eqs. (30) and (32). Figure 2 shows the aerosol backscatter coefficient, aerosol extinction coefficient and aerosol depolarization ratio at $532 \mathrm{~nm}$ for a flight in and around Mexico City on 15 March 2006. More details about the meteorological context and aerosol sources and transport in this case study are given by de Foy et al. (2011), who discuss comparisons of the Weather Research and Forecasting (WRF)-Flexpart aerosol transport model and the HSRL-1 measurements for this case. Enhancements of backscatter and extinction in the data curtains mostly indicate urban aerosol from the Mexico City Metropolitan Area. The aerosol depolarization ratio, which is an indicator of non-spherical particles, is elevated throughout much of the boundary layer, reflecting the influence of locally generated dust.

Most of the scene consists of varying amounts of dust and pollution. While de Foy et al. (2011) also show a significant amount of fresh smoke in the region, here we limit the analysis to the region below $4 \mathrm{~km}$ above mean sea level (a.s.l.) and no smoke plumes are included. Figure 3 shows the measurements on 15 March 2006 from HSRL-1 of three intensive variables for all data points below $4 \mathrm{~km}$ having extinction in excess of $0.05 \mathrm{~km}^{-1}$. Here, the aerosol depolarization ratio has been converted to depolarization potential, since this is the quantity that mixes linearly, according to Eq. (27). Note that the intensive variables are spread over a continuum in all three measurement dimensions, supporting the inference of an external mixture between two types. 

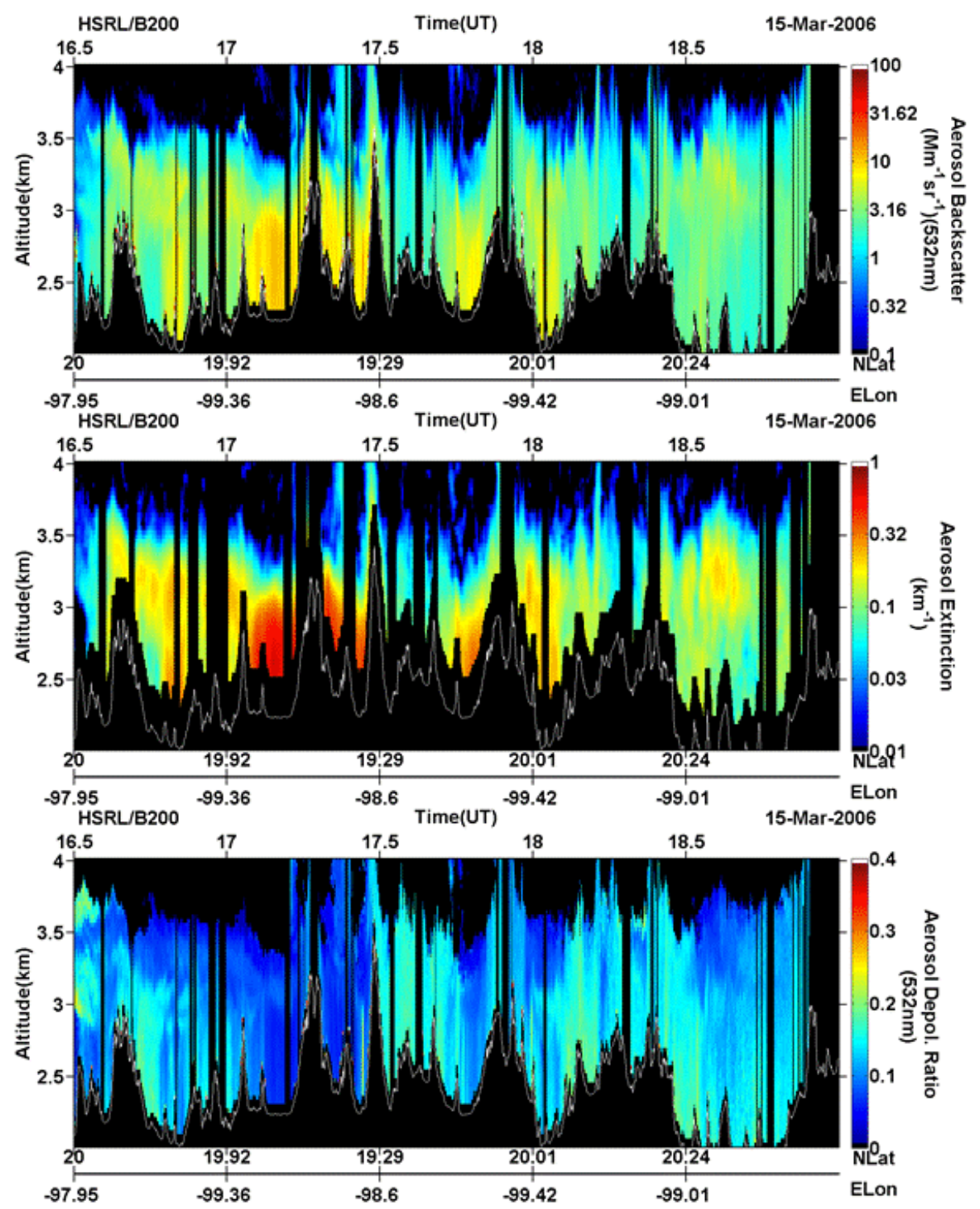

Fig. 2. HSRL-1 measurements of the aerosol backscattering coefficient at $532 \mathrm{~nm}$ (top), the aerosol extinction coefficient at $532 \mathrm{~nm}$ (middle) and the aerosol depolarization ratio, $\delta$, at $532 \mathrm{~nm}$ (bottom) are shown for a flight over Mexico City and surrounding regions on $15 \mathrm{March} 2006$ during the MILAGRO campaign. Black vertical lines indicate no data, usually due to shuttering the laser during aircraft turns or filtering data that is attenuated by clouds.

Measurement samples of pure types are required for analyzing the mixture according to Eqs. (30)-(32). For this study, we define the distributions for the pure types using scene-specific measurements, rather than using generic models. For pure dust, we take an HSRL-1 measurement sample of locally generated dust from a dust plume observed on the slope of Pico de Orizaba, $200 \mathrm{~km}$ east of Mexico City, three days earlier on 12 March (de Foy et al., 2011). The $532 \mathrm{~nm}$ lidar ratio of this measurement sample, $34 \pm 2 \mathrm{sr}$, is smaller than typical values reported for Saharan dust close to the source (Esselborn et al., 2009; Freudenthaler et al., 2009), but the high depolarization ratio, 0.32 , is comparable to the values of $0.27-0.35$ measured by Freudenthaler et al. (2009), suggesting this sample is indeed pure dust, though of a different composition than Saharan dust. The very low backscatter color ratio $(532 \mathrm{~nm} / 1064 \mathrm{~nm})$ of $0.70 \pm 0.07$ indicates large particles. Again, these values differ from other HSRL-1 measurements of pure dust which mostly correspond to transported Saharan dust (Burton et al., 2012). The smaller color ratios in this observation of dust in Mexico, directly at the source, probably imply the presence of large particles that have not yet deposited out of the plume. For this analysis, we also sample Mexico City urban pollution using the HSRL-1 aerosol classification mask (Burton et al., 2012) from an 
Table 1. The mean and standard deviation of the $532 \mathrm{~nm}$ aerosol lidar ratio, aerosol backscatter color ratio $(532 \mathrm{~nm} / 1064 \mathrm{~nm})$ and $532 \mathrm{~nm}$ aerosol depolarization potential are given for the six samples of pure aerosol types measured by the HSRL-1 airborne lidar that are discussed in this study. The mean aerosol depolarization ratio is also given, since this is a more familiar quantity. See Section 3 for definitions of aerosol depolarization ratio and depolarization potential.

\begin{tabular}{lcccc}
\hline & $\begin{array}{c}\text { Aerosol } \\
\text { lidar } \\
\text { ratio }(\mathrm{sr}) \\
(532 \mathrm{~nm})\end{array}$ & $\begin{array}{c}\text { Aerosol } \\
\text { backscatter } \\
\text { color ratio } \\
(532 \mathrm{~nm} / 1064 \mathrm{~nm})\end{array}$ & $\begin{array}{c}\text { Aerosol } \\
\text { depolarization } \\
\text { potential } \\
(532 \mathrm{~nm})\end{array}$ & $\begin{array}{c}\text { Aerosol } \\
\text { depolarization } \\
\text { ratio } \\
(532 \mathrm{~nm})\end{array}$ \\
\hline Mexico dust & $34 \pm 2$ & $0.70 \pm 0.07$ & $0.24 \pm 0.01$ & 0.32 \\
Mexico City pollution & $51 \pm 5$ & $1.8 \pm 0.1$ & $0.067 \pm 0.009$ & 0.072 \\
Caribbean marine & $21 \pm 3$ & $1.4 \pm 0.1$ & $0.05 \pm 0.02$ & 0.05 \\
Transported Saharan dust & $48 \pm 3$ & $1.6 \pm 0.1$ & $0.241 \pm 0.005$ & 0.32 \\
Yucatan Peninsula smoke & $66 \pm 6$ & $1.7 \pm 0.1$ & $0.025 \pm 0.001$ & 0.026 \\
Gulf of Mexico marine & $24 \pm 2$ & $1.1 \pm 0.1$ & $0.017 \pm 0.008$ & 0.017 \\
\hline
\end{tabular}

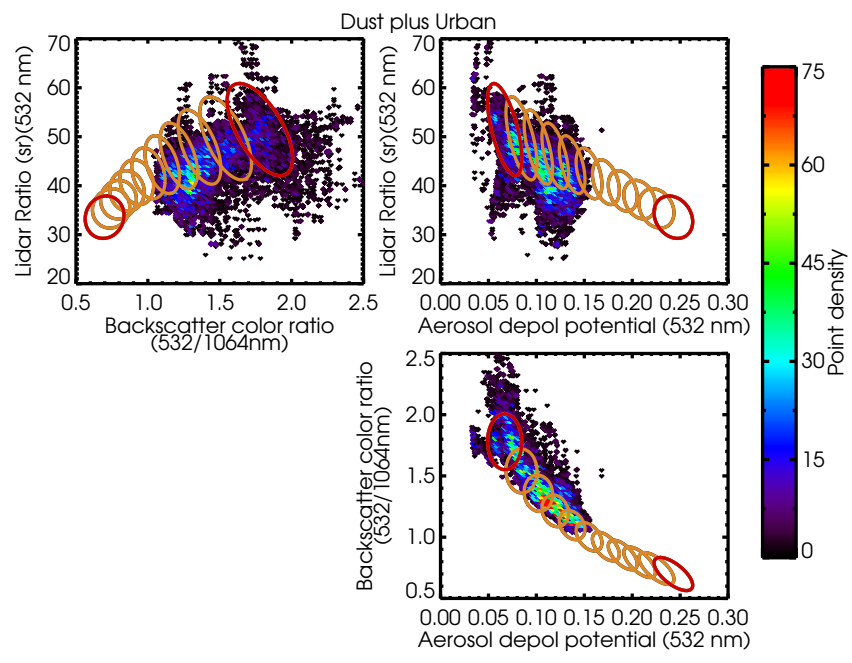

Fig. 3. Aerosol intensive parameters measured by HSRL-1 on 15 March 2006 in Mexico City and surrounding areas. All data below $4 \mathrm{~km}$ a.s.l. having $532 \mathrm{~nm}$ aerosol extinction greater than $0.05 \mathrm{~km}^{-1}$ are shown. The three panels illustrate three different combinations of two of the intensive parameters: $532 \mathrm{~nm}$ aerosol lidar ratio, backscatter color ratio $(532 / 1064 \mathrm{~nm})$ and $532 \mathrm{~nm}$ aerosol depolarization potential (see text for definition). The measurements are shown as individual points, color coded by point density in the 2-D space with warmer colors indicating higher point density (in arbitrary units). The red ellipses represent two-sigma covariance for pure dust and urban pollution (see text) and the orange ellipses indicate mixtures of the two with a range of mixing ratios.

overpass directly over Mexico City where the backscattering and extinction are at a maximum. In contrast to the dust, this sample has a higher lidar ratio, $51 \pm 5 \mathrm{sr}$, larger backscatter color ratio, $1.8 \pm 0.1$, and small depolarization ratio of 0.07 , consistent with other lidar measurements of urban aerosol (Burton et al., 2012, 2013; Groß et al., 2013a). These measurements are also shown in Table 1.
Numerically calculating the variance-covariance matrices for the pure-type measurement samples is straightforward. The ellipses representing the two-sigma covariance contours of the samples of pure dust and pure urban aerosol are shown in red in Fig. 3. Also shown, in orange, are ellipses representing covariance matrices for mixtures built using Eqs. (30)(32) with backscatter partitions, $p_{532}$, of $10,20,30 \ldots 90 \%$. The agreement between the measured data and the envelope of the string of ellipses can be taken as confirmation of the derivations in Sects. 3 and 4 and an indicator that the aerosol in this case is well represented as an external mixture.

The next step is to estimate the partitioning between the two aerosol types, in terms of the $532 \mathrm{~nm}$ extinction partition (or "extinction mixing ratio") for the entire flight at all altitudes. Given measured values of three aerosol intensive parameters, we could use any of the scalar Eqs. (16), (19), or (27) in Sect. 3 to estimate the extinction mixing ratio at each point. But to infer an extinction mixing ratio simultaneously consistent with all three measured variables, we instead use the calculated multivariate distributions illustrated in Fig. 3. Any value of the extinction mixing ratio is associated one-toone with a backscatter mixing ratio using Eq. 20 and with a multivariate distribution given by a vector mean and covariance matrix as described in Eqs. (30)-(32). A given measurement will be consistent with a range of overlapping multinormal distributions, but by minimizing the Mahalanobis distance as a function of mixing ratio, we choose the distribution that is the best match to a given measurement. The Mahalanobis distance (Mahalanobis, 1936), discussed in detail by Burton et al. (2012), is a generalized unitless metric that describes the "distance" between a measurement point and a multivariate normal distribution. This calculation, choosing the extinction mixing ratio that best fits a given observation, is exactly analogous to the aerosol classification methodology described by Burton et al. (2012). However, instead of eight aerosol types described by multi-normal distributions, here we have a continuum of multi-normal distributions 


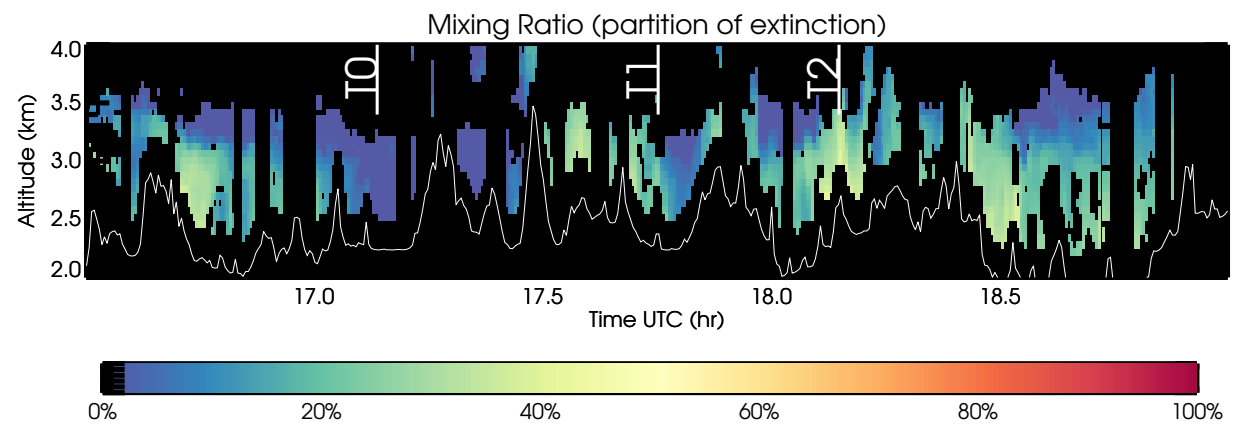

Fig. 4. Illustrates the extinction mixing ratio (percentage of $532 \mathrm{~nm}$ extinction due to dust) for the dust plus urban mixtures observed by HSRL-1 on 15 March 2006 during the MILAGRO field campaign. The extinction mixing ratio is inferred from the lidar measurements and Eqs. (30)-(32) as described in the text. The blue end of the color scale indicates more urban and the red end indicates more dust. Vertical lines indicate the closest approach to the three campaign ground sites, T0, T1 and T2.
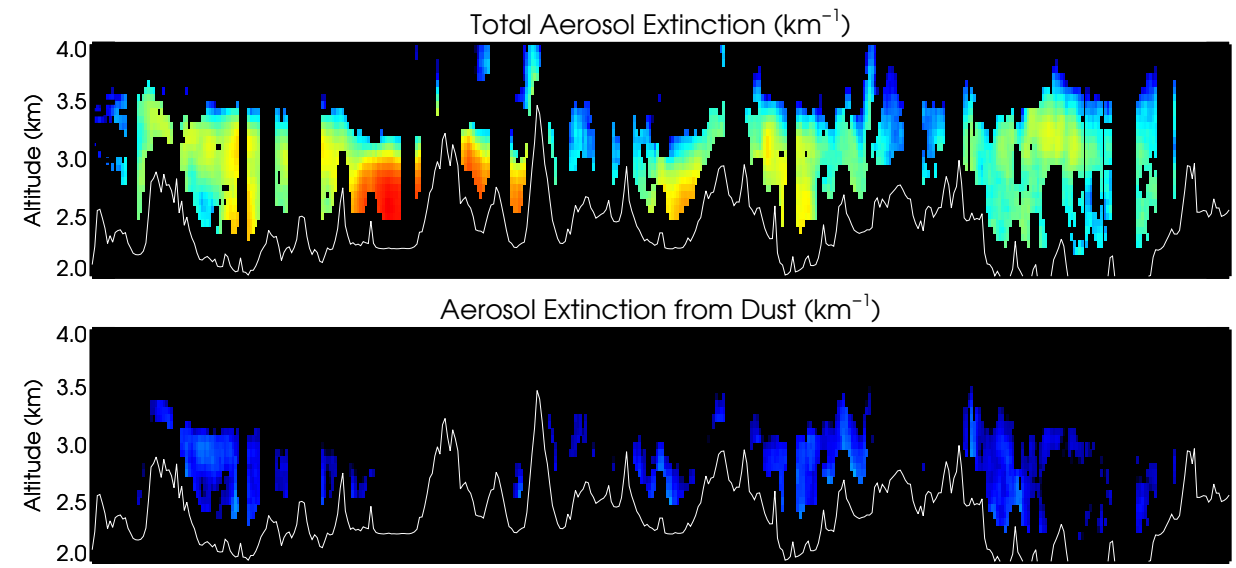

Aerosol Extinction from Urban $\left(\mathrm{km}^{-1}\right)$

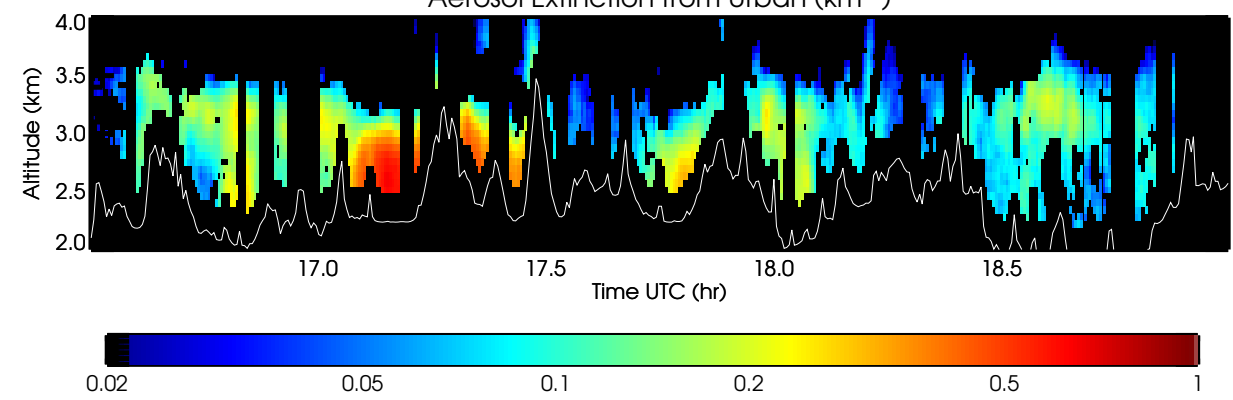

Fig. 5. Partition of extinction into contributions by the two pure types, dust and urban, for the HSRL-1 measurements on 15 March 2006. The top panel shows the total aerosol extinction; the middle panel shows the aerosol extinction attributed to dust; the lower panel shows the aerosol extinction attributed to urban pollution.

which sample the range of possible extinction mixing ratios from $0 \%$ to $100 \%$. We choose the single multi-normal distribution which minimizes the Mahalanobis distance metric and therefore maximizes the probability that the measurement is consistent with the distribution. Figure 4 shows a time-height cross-section of the inferred extinction mixing ratio, $f_{532}$, for this flight.
This procedure gives a best estimate of the extinction mixing ratio, but a given measurement point can be consistent with a range of overlapping mixture distributions. We therefore also calculate an uncertainty in the extinction mixing ratio estimate. The error in the extinction mixing ratio is affected by several factors. Errors in selecting or characterizing the pure type distributions would have a significant effect on the mixing ratio. A large error in the pure type distributions would be noticeable as a significant mismatch between the 

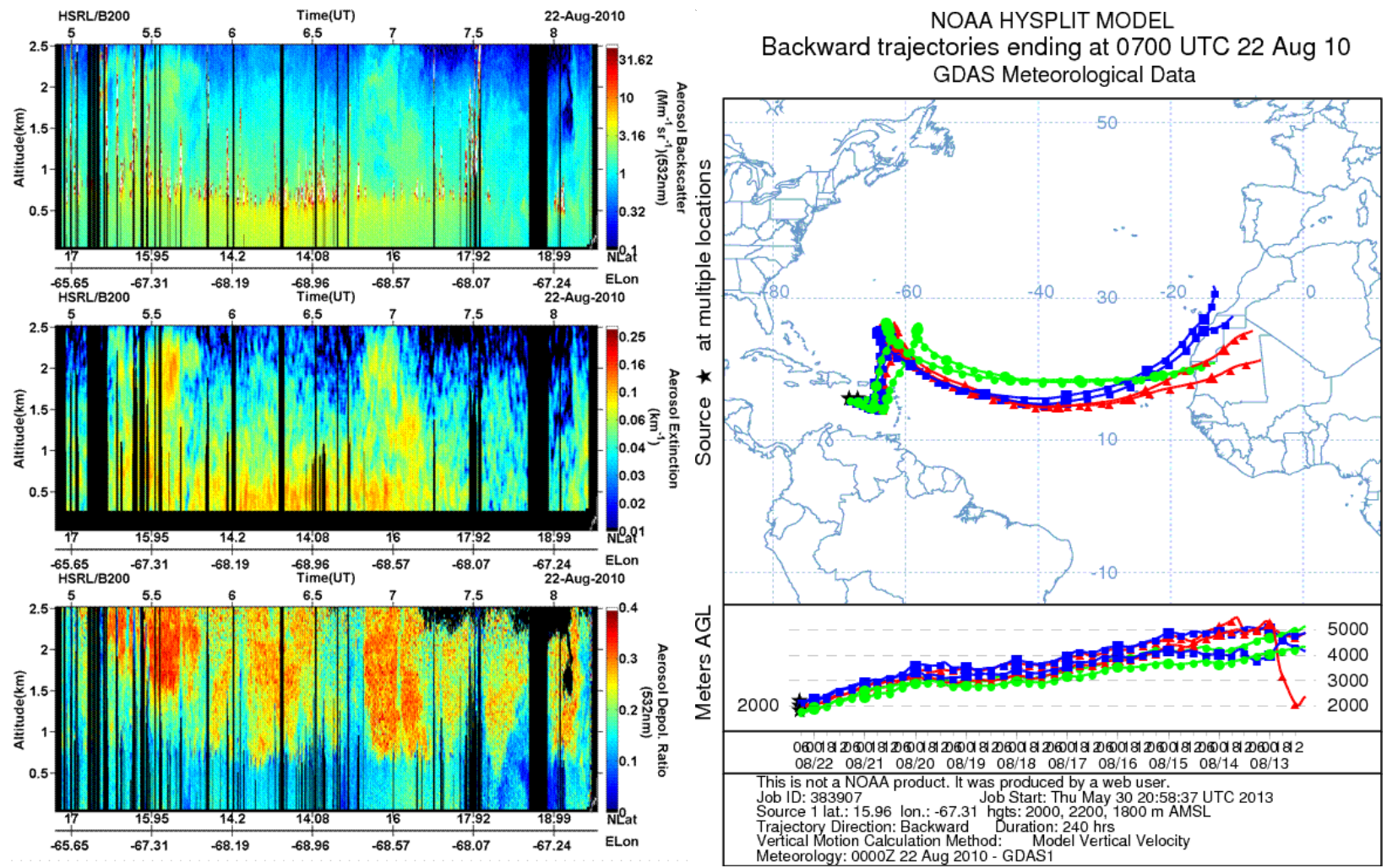

Fig. 6. HSRL-1 measurements (left three panels) of aerosol backscatter coefficient, aerosol extinction coefficient and aerosol depolarization ratio, $\delta$, on 22 August 2010 in the Caribbean Sea. High values of depolarization indicate a layer of transported Saharan dust, which is mixing with the marine boundary layer. On the right is a set of NOAA HYSPLIT back-trajectories ending within the observed dust layer; the trajectories lead back to Saharan Africa.

curvature of the data and the ellipses in Fig. 3; however, a smaller systematic error of this type may not be obvious and would be difficult to characterize. Measurement error in the pure type samples affects the size and shape of the ellipses but not the curves that link them, and so does not have a significant effect on the extinction mixing ratio. However, measurement uncertainty also affects the placement of the point to be characterized and will therefore lead to random error in the extinction mixing ratio. To estimate this error, we note that the minimized Mahalanobis distance is essentially a fitting residual. In order to convert the unitless Mahalanobis distance to mixing ratio units, we estimate a local scaling factor, using the Mahalanobis distance between the mixture distribution and the center of a neighboring distribution with a slightly different extinction mixing ratio. Extinction mixing ratio uncertainties for this example are approximately 3$10 \%$ mixing ratio (percentage points).

Vertical lines in Fig. 4 indicate the point of closest approach to the MILAGRO campaign's three measurement ground sites, T0, T1, and T2. In each case, the closest approach was within $10 \mathrm{~km}$ and $15 \mathrm{~min}$ of an Aerosol Robotic Network (AERONET) (Holben et al., 1998) observation. AERONET retrievals of coarse mode fraction (O'Neill et al., 2003) at these locations and times, converted to $532 \mathrm{~nm}$ using the AERONET-reported total and fine-mode Ångstrøm exponents, were $4 \% \pm 26 \%, 30 \% \pm 10 \%$, and $40 \% \pm 6 \%$ for $\mathrm{T} 0, \mathrm{~T} 1$, and $\mathrm{T} 2$, respectively (uncertainties are root mean square error in units of percentage points). Assuming the dust in this scene is predominantly coarse mode, then the inferred dust extinction mixing ratio in Fig. 4 for these three locations is in good agreement with these column values. For T0, the dust extinction mixing ratio inferred for every point in the column was $0 \% \pm 8 \%$. At T1, the inferred dust extinction mixing ratio varies from $18 \% \pm 5 \%$ to $23 \% \pm 4 \%$, with most of the column having values at the higher end of the range. At T2, most of the column has calculated dust extinction mixing ratios of $30 \% \pm 4 \%$ to $36 \% \pm 3 \%$, with a dropoff to $27 \% \pm 5 \%$ in the top $150 \mathrm{~m}$ of the aerosol column. For these locations and times, the HSRL-derived dust extinction mixing ratio is relatively constant throughout the column. However, Fig. 4 clearly shows in other parts of the scene, for example around 16:45 UT, 18:00 UT and again around $18: 30 \mathrm{UT}$, that there is significant vertical variability in the aerosol extinction mixing ratio. These vertical gradients cannot be captured by a passive instrument that retrieves only column-equivalent values. 
Figure 5 shows the contribution of each of the two pure types, dust and urban pollution, to the total measured aerosol extinction at $532 \mathrm{~nm}$, calculated by applying the mixing ratios from Fig. 4.

\section{HSRL-1 observations of dust and marine mixtures in the Caribbean Sea}

Another case of HSRL-1 observations of mixtures is shown in Fig. 6. On six days between 18 August and $27 \mathrm{Au}-$ gust 2010, HSRL-1 observed dust in the Caribbean transported from Africa. Some of these cases are discussed by Burton et al. $(2012$, 2013). The observations shown in Fig. 6 occurred on 22 August south of Puerto Rico at $13^{\circ}-19^{\circ} \mathrm{N}$ latitude, $65^{\circ}-69^{\circ} \mathrm{W}$ longitude. Back-trajectories calculated using the online Hybrid Single Particle Lagrangian Integrated Trajectory (HYSPLIT) tool from the NOAA Air Resources Laboratory READY website (http://ready.arl.noaa. gov/HYSPLIT.php; Draxler and Rolph, 2013) lead back to Saharan Africa approximately 10 days earlier. In this scene, the main part of the dust layer is at relatively low altitude, in contact with the marine boundary layer and mixing with it. This is evidenced by the depolarization-ratio curtain in Fig. 6, where the aerosol depolarization ratio exceeds 0.10 even in the marine boundary layer. The aerosol intensive parameters are shown in Fig. 7 for all measurements with extinction above $0.05 \mathrm{~km}^{-1}$ (again, aerosol depolarization ratio is converted to aerosol depolarization potential for Fig. 7). To analyze these measurements in terms of mixtures of dust plus marine aerosol, a pure dust sample was selected using the HSRL classification (Burton et al., 2012) from the part of this scene with the highest depolarization ratio, between 05:24 UT (5.4 UT) and 05:48 UT (5.8 UT) and between 1.4 and $2.4 \mathrm{~km}$ a.s.l. The measured depolarization ratio of this sample is again approximately 0.32 (which is 0.24 depolarization potential), the lidar ratio is $48 \pm 3 \mathrm{sr}$ and the backscatter color ratio is $1.6 \pm 0.1$ (see Table 1). David et al. (2013) claim that the maximum measured value of depolarization should not be used as a proxy for the depolarization of pure dust in cases of transport, since mixing with spherical particles will invariably occur, decreasing the depolarization value from that of pure dust. However, the peak depolarization ratio measurement is consistent with pure dust depolarization measurements in literature (Freudenthaler et al., 2009) and supports the use of this portion of the air mass being considered pure dust. On the other hand, the larger backscatter color ratio indicates a smaller mean particle size, smaller than the locally generated Mexican dust discussed in Sect. 5. This suggests that the largest particles have been lost to deposition during transport (Maring et al., 2003; Preißler et al., 2013). Aerosol depolarization ratio measurements greater than 0.10 throughout this scene suggest that there is no pure marine aerosol here. Therefore, the pure marine sample for this case was obtained from a flight on

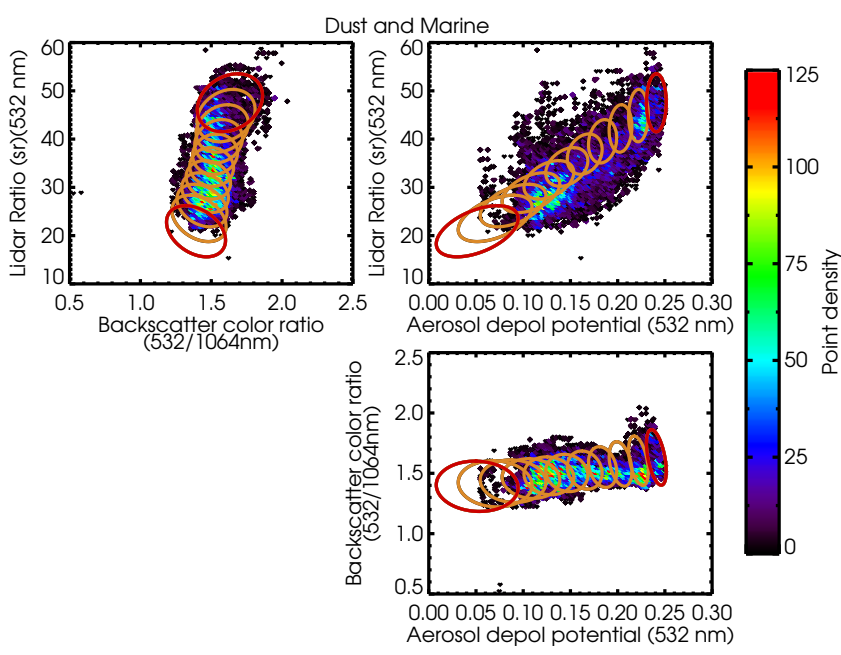

Fig. 7. Aerosol intensive parameters measured by HSRL-1 on 22 August 2010 in the Caribbean Sea south of Puerto Rico. The three panels show three different combinations of two of the intensive parameters, $532 \mathrm{~nm}$ aerosol lidar ratio, backscatter color ratio $(532 / 1064 \mathrm{~nm})$ and $532 \mathrm{~nm}$ aerosol depolarization potential (see text for definition). Measurements having $532 \mathrm{~nm}$ aerosol extinction greater than $0.05 \mathrm{~km}^{-1}$ are shown. The measurements are shown as individual points, color coded by point density in the 2-D space with warmer colors indicating higher point density (in arbitrary units). The red and orange ellipses represent two-sigma covariance for pure dust and marine (see text) and mixtures of the two with a range of mixing ratios.

26 August, four days later, in the same region. The aerosol intensive parameters for the pure marine sample are given in Table 1. The covariance matrices derived from the two samples of pure types are shown as red ellipses (two-sigma covariance) in Fig. 7.

Once again, the HSRL-1 measurements lie on a continuum between the two pure types and are in good agreement with the ellipses representing mixture multi-normal distributions from Eqs. (30)-(32). This alignment indicates that the observations are well described as a mixture between these two pure types. Note however that the pure types have been specified explicitly for each scene. In particular, there is a significant difference in lidar ratio and backscatter color ratio between the pure dust samples from the Mexico scene and the Caribbean scene. This should not be surprising since other researchers (Esselborn et al., 2009; Schuster et al., 2012; Mamouri et al., 2013) have found that the lidar ratio for dust depends on source region, and that the size distribution and Ångstrøm exponents change as large particles are removed during transport (Maring et al., 2003; Weinzierl et al., 2011; Preißler et al., 2013). If generic aerosol models were used in the mixture calculations, the results for the mixed state would be more approximate. The accuracy of the partitioning results depends on the accuracy of the models used. If the pure dust sample from Mexico City were used in place 

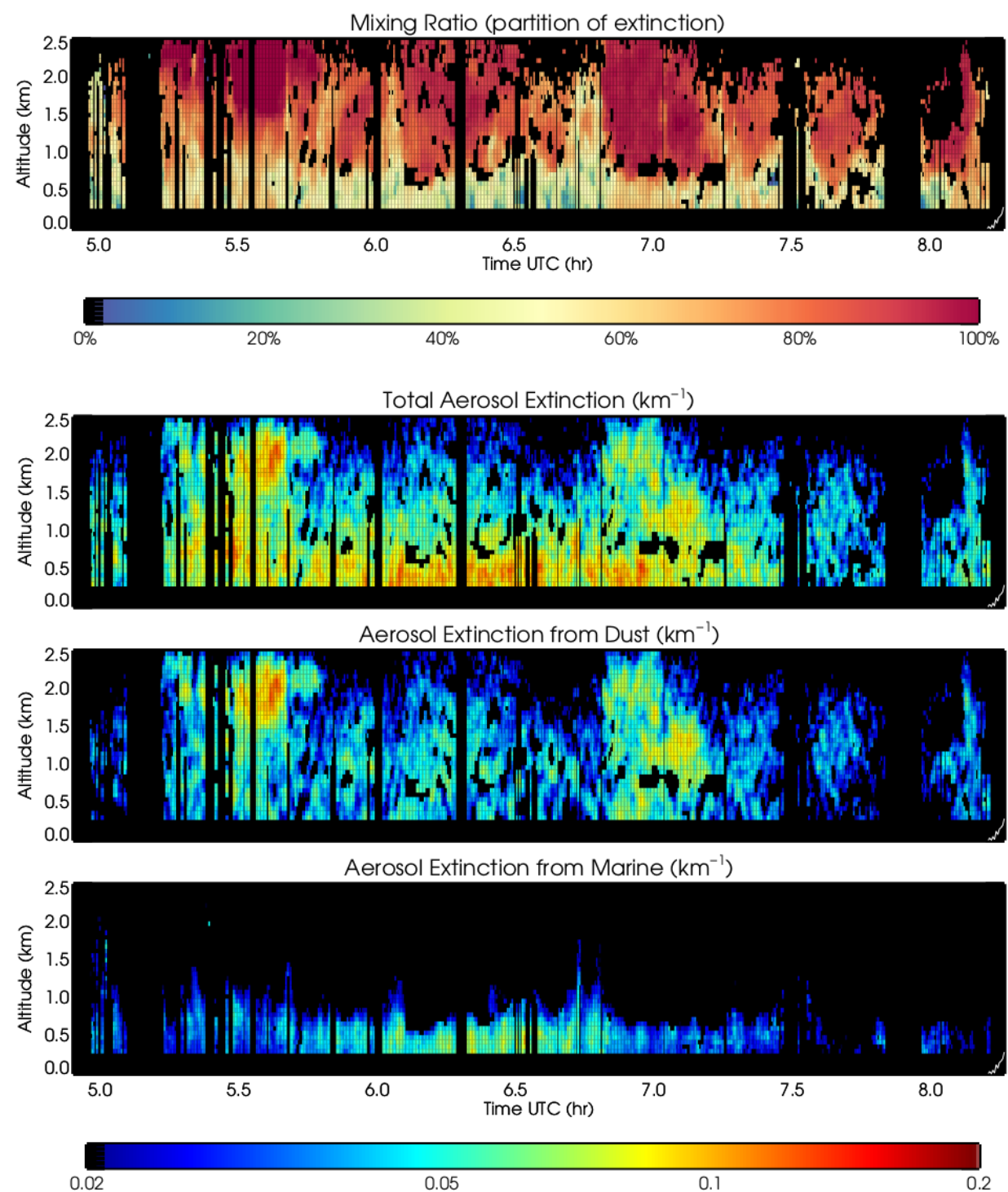

Fig. 8. Top panel illustrates the extinction mixing ratio (percentage of $532 \mathrm{~nm}$ extinction due to dust) for the mixtures of marine aerosol and transported Saharan dust observed by HSRL-1 on 22 August 2010 in the Caribbean Sea. The extinction mixing ratio is inferred from the lidar measurements and Eqs. (30)-(32) as described in the text. In this case, blue colors indicate more marine aerosol and red indicates more dust. Bottom three panels show aerosol extinction measurements and aerosol extinction apportioned to the dust and marine components separately.

of the Caribbean dust model in this scene, the ellipses would not line up well with the data, which would serve as an indication that the Mexico City dust model is not a good model for this scene of transported Saharan dust. For some applications, generic aerosol models may be unavoidable. Further study is required to determine how to best use generic models for specific applications, and how much effect they would have on the accuracy of the results.

Figure 8 shows the inferred extinction mixing ratio for this scene as a percentage of $532 \mathrm{~nm}$ extinction due to dust and shows the partitioning of extinction for this scene. The marine aerosol is confined to the boundary layer. While most of the aerosol extinction due to dust is in a lofted layer, there is a significant amount of dust aerosol also in the marine boundary layer, as expected.

\section{HSRL-1 observations of mixed smoke and marine aerosol in the Gulf of Mexico}

Our final case study occurred in the Gulf of Mexico near Veracruz on 28 March 2006, also during the MILAGRO field campaign. Figure 9 shows HSRL-1 measurement curtains and NOAA Hysplit 10-day back-trajectories for this scene. The aerosol in the boundary layer consists of two layers. 

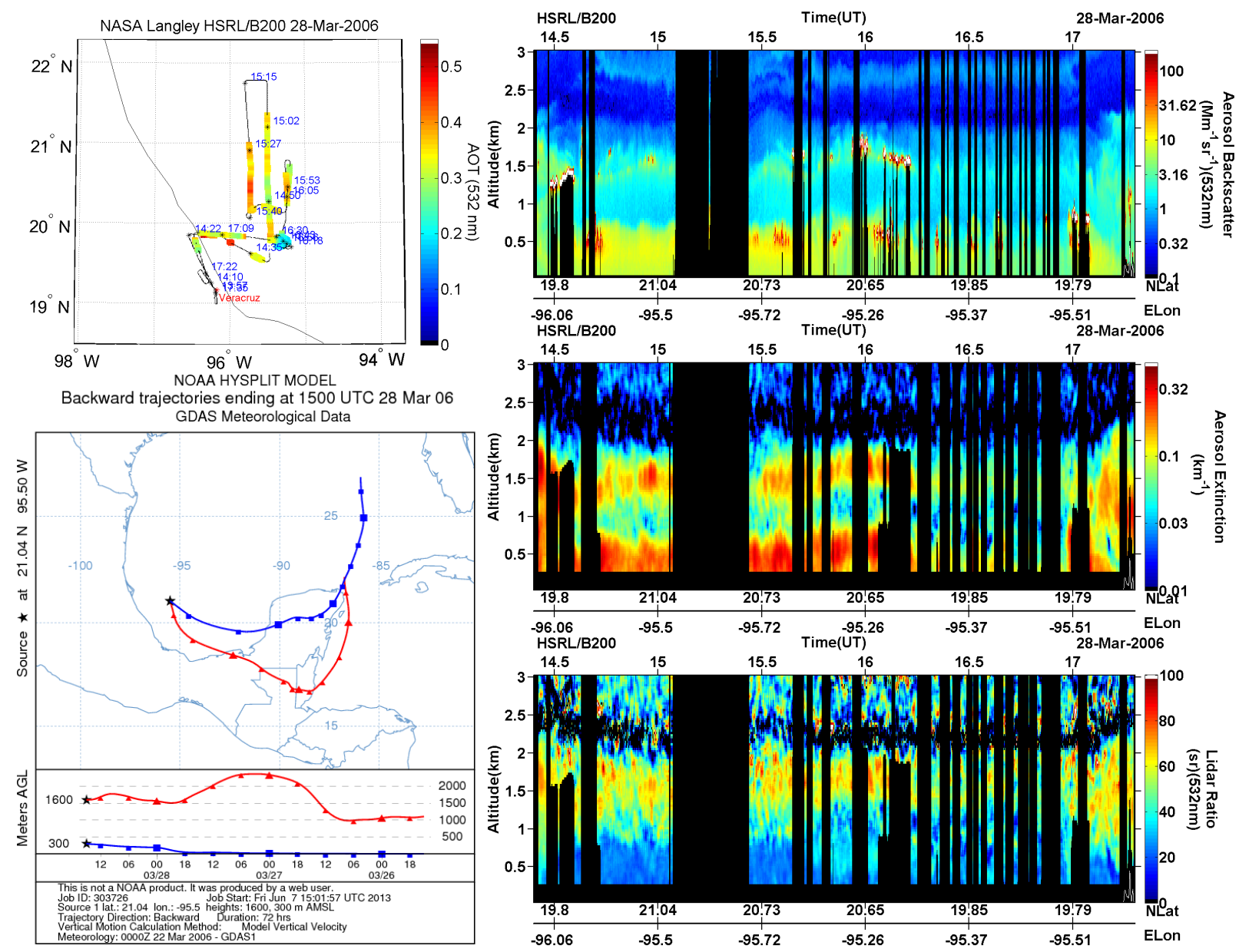

Fig. 9. Overview of observations on the 28 March 2006 flight off the coast of Mexico near Veracruz. Panel (a) shows a map of the HSRL flight track, color coded by total column AOT. Panel (b) shows 10-day back-trajectories for two points in the boundary layer (1600 m a.s.1. and $300 \mathrm{~m}$ a.s.1.) at 15:00 UT. Panels (c)-(e) show HSRL observations of aerosol backscatter, aerosol extinction and aerosol lidar ratio at 532 nm. The stratification in the lidar ratio with higher values in the upper part of the boundary layer and lower values in the lower part is indicative of a smoke or pollution layer on top of a layer of marine air. The two layers are in contact and show intermediate values of lidar ratio at altitudes in the middle of the boundary layer.

The lower layer has the properties of marine aerosol (Burton et al., 2012, 2013) with low lidar ratios near 24 sr. The upper layer, from an air mass which crossed the Yucatan peninsula $24-48 \mathrm{~h}$ before the time of observation, has higher lidar ratios of $60-70 \mathrm{sr}$ consistent with pollution or smoke (e.g., Tesche et al., 2011; Burton et al., 2012, 2013). Figure 10 shows the aerosol lidar ratio and backscatter color ratio for measurements below $2500 \mathrm{~m}$ a.s.l. and having extinction greater than $0.05 \mathrm{~km}^{-1}$. The backscatter color ratio increases with lidar ratio such that larger particles are associated with the lower lidar ratios (marine) and smaller particles are associated with higher lidar ratios (smoke or pollution). Considering the prevalence of small fires in the region (Fast et al., 2007), the air mass is probably best described as smoke aerosol. Both Figs. 9 and 10 show that the marine and smoke aerosol types are not cleanly separated. At altitudes in the middle of the boundary layer, the lidar ratio and backscatter color ratio take on intermediate values. This suggests that there is mixing between the two types.

There is no dust in this scene and insignificant aerosol depolarization. Therefore the technique of Sugimoto and Lee (2006), Tesche et al. (2009, 2011) and Groß et al. (2011) for separating aerosol into dust and non-dust components would not be applicable in this case. In contrast, the generalized technique presented in this study uses multiple aerosol intensive parameters and does not require measurable depolarization. We therefore performed our separation technique for this case using only the lidar ratio and backscatter color ratio shown in Fig. 10.

As with dust, smoke aerosol properties are known to vary according to the source region, age and transport (AladosArboledas et al., 2011; Nicolae et al., 2013), including dramatic variability in the lidar ratio. Again, this variability motivates our decision to use aerosol models specific to this 


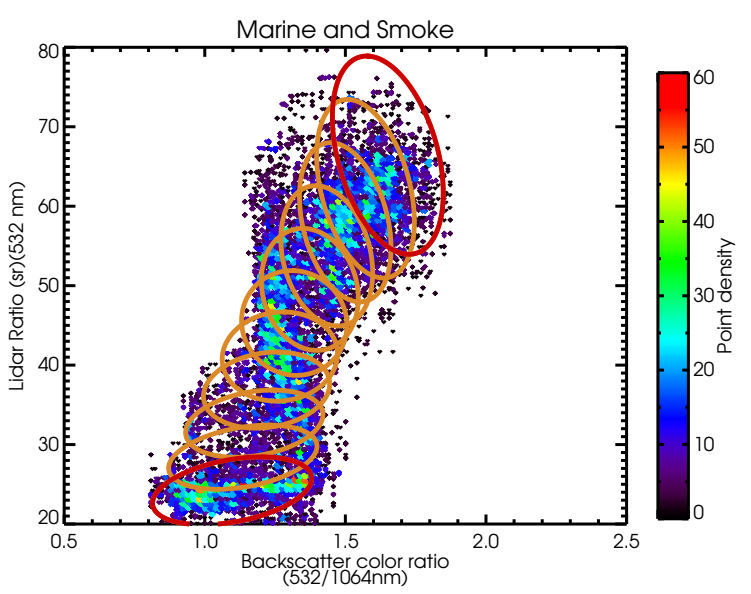

Fig. 10. Aerosol lidar ratio $(532 \mathrm{~nm})$ and backscatter color ratio (532/1064 nm) measured by HSRL-1 on 28 March 2006 in the Gulf of Mexico. All measurements on this flight below $2500 \mathrm{~m}$ a.s.l. and having extinction greater than $0.05 \mathrm{~km}^{-1}$ are shown in this figure. The measurements are shown as individual points, color coded by point density with warmer colors indicating higher point density (in arbitrary units). The red and orange ellipses represent two-sigma covariance for pure smoke and pure marine (see text) and for mixtures of the two with a range of mixing ratios.

region. The covariance matrices for the pure types were both taken from measurement samples in this flight. The smoke sample is taken from between 1.5 and $2.0 \mathrm{~km}$ a.s.l. from the start of the flight before 14:28 UT (14.46 UT) where elevated aerosol extinction levels indicate higher aerosol loading. The marine sample was obtained below $0.7 \mathrm{~km}$ a.s.l. between 14:48 UT (14.8 UT) and 15:12 UT (15.2 UT) where the lidar ratio is low and has relatively little variability. The inferred extinction mixing ratio and partition of extinction are shown in Fig. 11. As expected, most of the extinction in the lower part of the layer is attributed to marine aerosol and most of the extinction in the upper part of the layer is attributed to smoke aerosol, but with some portions of the curtains having partial contributions from both types.

\section{Summary and outlook}

In summary, we show that lidar observable aerosol intensive parameters frequently reflect mixtures between different aerosol types. We expand the derivations of equations used by previous researchers to describe external mixtures. The equations for each observable can be written in the form of a linear combination of pure types, from which follow equations for multivariate covariance matrices. Therefore we can precisely describe mixing rules not only for single measurements but also measurement distributions. We also give the relationships between the mixing coefficients for different intensive quantities at different wavelengths.
It is important to acknowledge that not all variability in aerosol is due to external mixing. Humidification of aerosol (Su et al., 2008; Ferrare et al., 2001; Howell et al., 2006), aging and deposition during transport (Maring et al., 2003; Weinzierl et al., 2011), and internal mixing (Lesins et al., 2002; Mishchenko et al., 2012) are other mechanisms that affect aerosol intensive parameters, in ways which may not conform to the relationships presented here. However, we show three example flights where good agreement between the lidar measurements and the analytical relationships support the assumption of external mixing: of pollution plus dust, dust plus marine, and smoke plus marine. We also apply the equations to infer time-height cross-sections of extinction mixing ratio and partitions of extinction, which is possible even for cases which do not include dust (and therefore which have insignificant depolarization).

Unlike most passive instruments which give only total column amounts of aerosol-relevant measurements, lidar measurements are fully resolved vertically. The ability to quantitatively apportion aerosol extinction to type in a vertically resolved measurement has the potential to greatly increase the information content that can be used for comparison and validation of global and regional aerosol models and chemical transport models. Models are the usual means of assessing the impact of aerosol on climate and air quality, but there is significant disagreement in how models represent the vertical distribution of aerosols (Textor et al., 2006; Koffi et al., 2012) and aerosol composition (Kinne et al., 2006; Shindell et al., 2012) even when similar emission functions are used (Textor et al., 2007). The aerosol classification from the NASA Langley airborne HSRL has previously been used to help evaluate and interpret aerosol models (e.g., de Foy et al., 2011). The ability to handle mixtures of aerosol types can potentially increase the usefulness of such comparisons, by providing more precise information on the vertical apportionment of aerosol by type. For example, using the standard HSRL-1 aerosol classification (Burton et al., 2012), most of the Caribbean scene illustrated in Figs. 6-8 is classified qualitatively as "dusty mix". The ability to quantify the amount of extinction in the marine boundary layer which is due to dust can give information on the deposition of aerosol which can improve our understanding of aerosol transformation during transport and relates to measurements of primary productivity in the ocean.

Applications relating to climate science can be challenging for aircraft measurements, which are necessarily limited in time and space. However, the work presented suggests that a $2 \beta+1 \alpha+2 \delta$ HSRL instrument (that is, an instrument with backscatter, extinction, and depolarization channels similar to the airborne HSRL-1) on a space platform could be used to quantitatively partition extinction by type in cases of external mixing on a global basis. Such an instrument is possible with today's technology, and could have significant potential for furthering our current understanding of climate through improvements to and validation of global models. 

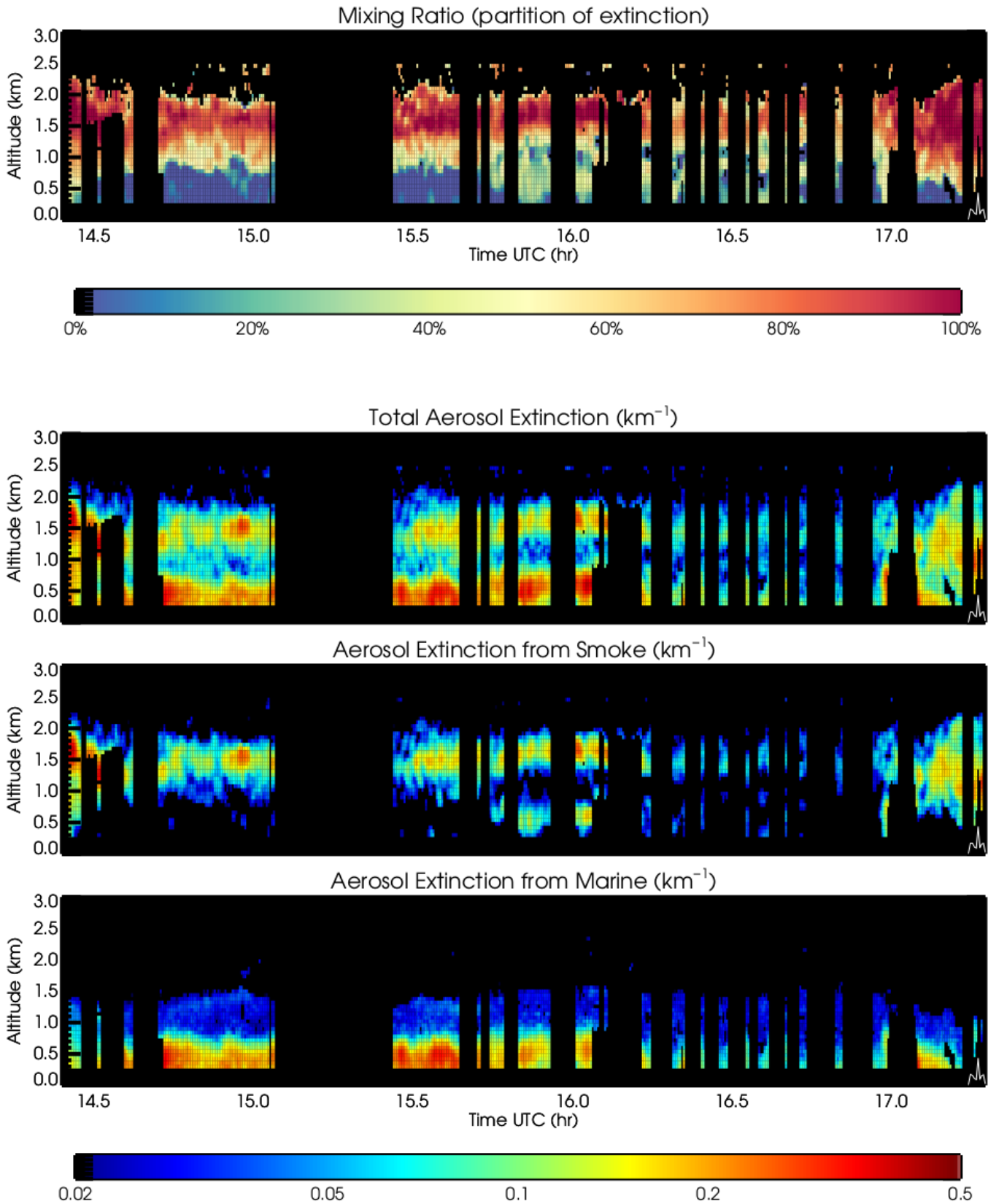

Fig. 11. Top shows extinction mixing ratio (percentage of $532 \mathrm{~nm}$ extinction due to smoke) for the mixtures of marine and smoke aerosol observed by HSRL-1 on 28 March 2006 in the Gulf of Mexico. The extinction mixing ratio is inferred from the measurements and Eqs. (30)(32) as described in the text. Blue indicates marine and red is smoke. Bottom three panels show the partition of aerosol extinction at $532 \mathrm{~nm}$ into separate contributions by marine and smoke.

The CALIPSO satellite lidar has provided global, vertically resolved measurements of aerosol from space since 2006. However, due to its smaller number of measurement channels, aerosol extinction cannot be calculated without external information or assumptions. Some methods for providing more accurate aerosol extinction profiles from CALIPSO use column aerosol optical thickness as a constraint (e.g., Josset et al., 2010; Burton et al., 2010). This technique avoids the need to infer a lidar ratio but does still require the assumption of a uniform aerosol mixture throughout the column. Calculations of mixtures from coincident HSRL-1 measurements on validation flights could potentially be used to help assess where and when this assumption is valid.

The current technique can be readily extended to accommodate additional measurements. NASA Langley has recently built and deployed a $3 \beta+2 \alpha+3 \delta$ HSRL 
instrument, HSRL-2, which makes measurements of extinction, backscatter, and depolarization at $355 \mathrm{~nm}$ in addition to the measurements made by HSRL-1. The extra aerosol parameters from the airborne or a future spaceborne lidar with this capability are expected to improve the accuracy of aerosol mixing ratio estimates. Moreover, the second wavelength of extinction and backscatter measurements enables advanced microphysical retrievals (Müller et al., 1999), and the methods described here can improve those retrievals. The large search space of these microphysical retrievals can be constrained by quantitative calculations of aerosol partitioning from the much simpler calculations presented in this paper, potentially making them both faster and more accurate (Veselovskii et al., 2013). We plan to explore this combination of techniques using data from the HSRL-2 instrument from past and future campaigns.

Finally, we note that altitude-resolved aerosol mixing ratio from a spaceborne lidar similar to HSRL-1 or HSRL-2 could prove useful as a constraint for retrievals from coincident radiometer or, in particular, multi-angle polarimeter measurements. Such a combination of instruments is indeed called for on NASA's ACE mission, and we anticipate exploring joint lidar-polarimeter retrieval approaches using data from the airborne HSRL instruments and coincidentally acquired polarimeter data from past and future field campaigns.

Acknowledgements. Funding for this research came from the NASA HQ Science Mission Directorate Radiation Sciences Program and the NASA CALIPSO project. The authors also acknowledge the NOAA Air Resources Laboratory (ARL) for the provision of the HYSPLIT transport and dispersion model and READY website (http://www.arl.noaa.gov/ready.php) used for some of the analysis described in this presentation, and we thank Brent Holben for establishing and maintaining the AERONET stations at the MILAGRO ground sites. Credit is owed to Cindy Brewer for the red-yellow-blue color set used in the mixing ratio plots. The authors are also very grateful to the NASA Langley B200 King Air flight crew for their outstanding work in support of HSRL measurements, and our HSRL engineering and analysis teams, in particular, Tony Cook, David Harper, Rich Hare, John Hair, Ray Rogers, Amy Jo Scarino, and Mike Obland, for building these excellent instruments, operating them in flight, and processing the measurements. Finally, we would like to thank Brian Cairns (NASA GISS) and Larry Thomason (NASA LaRC) for helpful discussions about the derivations presented in this paper.

Edited by: G. Pappalardo

\section{References}

Bevington, P. R. and Robinson, D. K.: Data Reduction and Error Analysis for the Physical Sciences, 2nd Edn., McGraw-Hill Inc., 328 pp., 1992.

Burton, S. P., Ferrare, R. A., Hostetler, C. A., Hair, J. W., Kittaka, C., Vaughan, M. A., Obland, M. D., Rogers, R. R., Cook, A. L., Harper, D. B., and Remer, L. A.: Using airborne high spectral resolution lidar data to evaluate combined active plus passive retrievals of aerosol extinction profiles, J. Geophys. Res.-Atmos., 115, D00H15, doi:10.1029/2009jd012130, 2010.

Burton, S. P., Ferrare, R. A., Hostetler, C. A., Hair, J. W., Rogers, R. R., Obland, M. D., Butler, C. F., Cook, A. L., Harper, D. B., and Froyd, K. D.: Aerosol Classification of Airborne High Spectral Resolution Lidar Measurements - Methodology and Examples, Atmos. Meas. Tech., 5, 73-98, doi:10.5194/amt-5-73-2012, 2012.

Burton, S. P., Ferrare, R. A., Vaughan, M. A., Omar, A. H., Rogers, R. R., Hostetler, C. A., and Hair, J. W.: Aerosol classification from airborne HSRL and comparisons with the CALIPSO vertical feature mask, Atmos. Meas. Tech., 6, 13971412, doi:10.5194/amt-6-1397-2013, 2013.

Cairo, F., Di Donfrancesco, G., Adriani, A., Pulvirenti, L., and Fierli, F.: Comparison of Various Linear Depolarization Parameters Measured by Lidar, Appl. Optics, 38, 4425-4432, 1999.

Cattrall, C., Reagan, J., Thome, K., and Dubovik, O.: Variability of aerosol and spectral lidar and backscatter and extinction ratios of key aerosol types derived from selected Aerosol Robotic Network locations, J. Geophys. Res.-Atmos., 110, D10S11, doi:10.1029/2004jd005124, 2005.

David, G., Thomas, B., Nousiainen, T., Miffre, A., and Rairoux, P.: Retrieving simulated volcanic, desert dust and sea-salt particle properties from two/three-component particle mixtures using UV-VIS polarization lidar and T matrix, Atmos. Chem. Phys., 13, 6757-6776, doi:10.5194/acp-13-6757-2013, 2013.

de Foy, B., Burton, S. P., Ferrare, R. A., Hostetler, C. A., Hair, J. W., Wiedinmyer, C., and Molina, L. T.: Aerosol plume transport and transformation in high spectral resolution lidar measurements and WRF-Flexpart simulations during the MILAGRO Field Campaign, Atmos. Chem. Phys., 11, 3543-3563, doi:10.5194/acp-11-3543-2011, 2011.

Draxler, R. R. and Rolph, G. D.: HYSPLIT (HYbrid Single-Particle Lagrangian Integrated Trajectory) Model access via NOAA ARL READY Website, available at: http://ready.arl.noaa.gov/ HYSPLIT.php (last access: 4 September 2013), NOAA Air Resources Laboratory, Silver Spring, MD, 2013.

Esselborn, M., Wirth, M., Fix, A., Weinzierl, B., Rasp, K., Tesche, M., and Petzold, A.: Spatial distribution and optical properties of Saharan dust observed by airborne high spectral resolution lidar during SAMUM 2006, Tellus B, 61, 131-143, doi:10.1111/j.1600-0889.2008.00394.x, 2009.

Fast, J. D., de Foy, B., Acevedo Rosas, F., Caetano, E., Carmichael, G., Emmons, L., McKenna, D., Mena, M., Skamarock, W., Tie, X., Coulter, R. L., Barnard, J. C., Wiedinmyer, C., and Madronich, S.: A meteorological overview of the MILAGRO field campaigns, Atmos. Chem. Phys., 7, 2233-2257, doi:10.5194/acp-7-2233-2007, 2007.

Fernald, F. G.: Analysis of Atmospheric Lidar Observations - Some Comments, Appl. Optics, 23, 652-653, 1984.

Ferrare, R., Turner, D. D., Brasseur, L. H., Feltz, W. F., Dubovik, O., and Tooman, T. P.: Raman lidar measurements of the aerosol extinction-to-backscatter ratio over the Southern Great Plains, J. Geophys. Res.-Atmos., 106, 20333-20347, 2001.

Freudenthaler, V., Esselborn, M., Wiegner, M., Heese, B., Tesche, M., Ansmann, A., Muller, D., Althausen, D., Wirth, M., Fix, A., Ehret, G., Knippertz, P., Toledano, C., Gasteiger, J., Garhammer, M., and Seefeldner, M.: Depolarization ratio profiling at several 
wavelengths in pure Saharan dust during SAMUM 2006, Tellus Ser. B-Chem. Phys. Meteorol., 61, 165-179, doi:10.1111/j.16000889.2008.00396.x, 2009.

Gasteiger, J., Wiegner, M., Groß, S., Freudenthaler, V., Toledano, C., Tesche, M., and Kandler, K.: Modelling lidar-relevant optical properties of complex mineral dust aerosols, Tellus B, 63, 725741, doi:10.1111/j.1600-0889.2011.00559.x, 2011.

Gimmestad, G. G.: Reexamination of depolarization in lidar measurements, Appl. Optics, 47, 3795-3802, 2008.

Groß, S., Tesche, M., Freudenthaler, V., Toledano, C., Wiegner, M., Ansmann, A., Althausen, D., and Seefeldner, M.: Characterization of Saharan dust, marine aerosols and mixtures of biomassburning aerosols and dust by means of multi-wavelength depolarization and Raman lidar measurements during SAMUM 2, Tellus B, 63, 706-724, doi:10.1111/j.1600-0889.2011.00556.x, 2011.

Groß, S., Esselborn, M., Abicht, F., Wirth, M., Fix, A., and Minikin, A.: Airborne high spectral resolution lidar observation of pollution aerosol during EUCAARI-LONGREX, Atmos. Chem. Phys., 13, 2435-2444, doi:10.5194/acp-13-2435-2013, 2013 a.

Groß, S., Esselborn, M., Weinzierl, B., Wirth, M., Fix, A., and Petzold, A.: Aerosol classification by airborne high spectral resolution lidar observations, Atmos. Chem. Phys., 13, 2487-2505, doi:10.5194/acp-13-2487-2013, 2013b.

Grund, C. J. and Eloranta, E. W.: University-of-Wisconsin High Spectral Resolution Lidar, Opt. Eng., 30, 6-12, 1991.

Hair, J. W., Hostetler, C. A., Cook, A. L., Harper, D. B., Ferrare, R. A., Mack, T. L., Welch, W., Izquierdo, L. R., and Hovis, F. E.: Airborne High Spectral Resolution Lidar for profiling aerosol optical properties, Appl. Optics, 47, 6734-6752, doi:10.1364/AO.47.006734, 2008.

Hansen, J., Sato, M., and Ruedy, R.: Radiative forcing and climate response, J. Geophys. Res.-Atmos., 102, 6831-6864, 1997.

Holben, B. N., Eck, T. F., Slutsker, I., Tanré, D., Buis, J. P., Setzer, A., Vermote, E., Reagan, J. A., Kaufman, Y. J., Nakajima, T., Lavenu, F., Jankowiak, I., and Smirnov, A.: AERONET - A federated instrument network and data archive for aerosol characterization, Remote Sens. Environ., 66, 1-16, 1998.

Howell, S. G., Clarke, A. D., Shinozuka, Y., Kapustin, V., McNaughton, C. S., Huebert, B. J., Doherty, S. J., and Anderson, T. L.: Influence of relative humidity upon pollution and dust during ACE-Asia: Size distributions and implications for optical properties, J. Geophys. Res.-Atmos., 111, D06205, doi:10.1029/2004jd005759, 2006.

IPCC: Changes in Atmospheric Constituents and in Radiative forcing in Climate Change 2007, Cambridge University Press, New York, 2007.

Josset, D., Pelon, J., and Hu, Y.: Multi-Instrument Calibration Method Based on a Multiwavelength Ocean Surface Model, Geosci. Remote Sens. Lett., IEEE, 7, 195-199, doi:10.1109/lgrs.2009.2030906, 2010.

Kaufman, Y. J., Tanre, D., Leon, J. F., and Pelon, J.: Retrievals of profiles of fine and coarse aerosols using lidar and radiometric space measurements, Geoscience and Remote Sensing, IEEE Trans., 41, 1743-1754, doi:10.1109/tgrs.2003.814138, 2003.

Kinne, S., Schulz, M., Textor, C., Guibert, S., Balkanski, Y., Bauer, S. E., Berntsen, T., Berglen, T. F., Boucher, O., Chin, M., Collins, W., Dentener, F., Diehl, T., Easter, R., Feichter, J., Fillmore, D., Ghan, S., Ginoux, P., Gong, S., Grini, A., Hendricks, J., Herzog, M., Horowitz, L., Isaksen, I., Iversen, T., Kirkevåg, A., Kloster,
S., Koch, D., Kristjansson, J. E., Krol, M., Lauer, A., Lamarque, J. F., Lesins, G., Liu, X., Lohmann, U., Montanaro, V., Myhre, G., Penner, J., Pitari, G., Reddy, S., Seland, O., Stier, P., Takemura, T., and Tie, X.: An AeroCom initial assessment - optical properties in aerosol component modules of global models, Atmos. Chem. Phys., 6, 1815-1834, doi:10.5194/acp-6-1815-2006, 2006.

Koffi, B., Schulz, M., Bréon, F.-M., Griesfeller, J., Winker, D., Balkanski, Y., Bauer, S., Berntsen, T., Chin, M., Collins, W. D., Dentener, F., Diehl, T., Easter, R., Ghan, S., Ginoux, P., Gong, S., Horowitz, L. W., Iversen, T., Kirkevåg, A., Koch, D., Krol, M., Myhre, G., Stier, P., and Takemura, T.: Application of the CALIOP layer product to evaluate the vertical distribution of aerosols estimated by global models: AeroCom phase I results, J. Geophys. Res., 117, D10201, doi:10.1029/2011jd016858, 2012.

Léon, J. F., Tanré, D., Pelon, J., Kaufman, Y. J., Haywood, J. M., and Chatenet, B.: Profiling of a Saharan dust outbreak based on a synergy between active and passive remote sensing, J. Geophys. Res.-Atmos., 108, 8575, doi:10.1029/2002jd002774, 2003.

Lesins, G., Chylek, P., and Lohmann, U.: A study of internal and external mixing scenarios and its effect on aerosol optical properties and direct radiative forcing, J. Geophys. Res.-Atmos., 107, AAC5-1-AAC5-12, doi:10.1029/2001jd000973, 2002.

Mahalanobis, P. C.: On the Generalized Distance in Statistics, Proceedings of the National Institute of Sciences in India, 2, 49-55, 1936.

Mamouri, R. E., Ansmann, A., Nisantzi, A., Kokkalis, P., Schwarz, A., and Hadjimitsis, D.: Low Arabian dust extinctionto-backscatter ratio, Geophys. Res. Lett., 40, 4762-4766, doi:10.1002/grl.50898, 2013.

Maring, H., Savoie, D. L., Izaguirre, M. A., Custals, L., and Reid, J. S.: Mineral dust aerosol size distribution change during atmospheric transport, J. Geophys. Res.-Atmos., 108, 8592, doi:10.1029/2002jd002536, 2003.

Mishchenko, M. I., Liu, L., and Mackowski, D. W.: T-matrix modeling of linear depolarization by morphologically complex soot and soot-containing aerosols, J. Quant. Spectrosc. Ra., 123, 135144, doi:10.1016/j.jqsrt.2012.11.012, 2012.

Müller, D., Wandinger, U., and Ansmann, A.: Microphysical particle parameters from extinction and backscatter lidar data by inversion with regularization: simulation, Appl. Optics, 38, 23582368, 1999.

Nishizawa, T., Sugimoto, N., Matsui, I., Shimizu, A., and Okamoto, H.: Algorithms to retrieve optical properties of three component aerosols from two-wavelength backscatter and onewavelength polarization lidar measurements considering nonsphericity of dust, J.. Quant. Spectr. Radiat. Trans., 112, 254 267, doi:10.1016/j.jqsrt.2010.06.002, 2011.

Omar, A. H., Winker, D. M., Kittaka, C., Vaughan, M. A., Liu, Z. Y., Hu, Y. X., Trepte, C. R., Rogers, R. R., Ferrare, R. A., Lee, K. P., Kuehn, R. E., and Hostetler, C. A.: The CALIPSO Automated Aerosol Classification and Lidar Ratio Selection Algorithm, J. Atmos. Ocean. Tech., 26, 1994-2014, doi:10.1175/2009jtecha1231.1, 2009.

O’Neill, N. T., Eck, T. F., Smirnov, A., Holben, B. N., and Thulasiraman, S.: Spectral discrimination of coarse and fine mode optical depth, J. Geophys. Res.-Atmos., 108, 4559, doi:10.1029/2002jd002975, 2003. 
Parois, P. and Lutz, M.: Linear transformations of variance/covariance matrices, Acta Crystallogr. A, 67, 383-390, doi:10.1107/S0108767311018216, 2011.

Petzold, A., Veira, A., Mund, S., Esselborn, M., Kiemle, C., Weinzierl, B., Hamburger, T., Ehret, G., Lieke, K., and Kandler, K.: Mixing of mineral dust with urban pollution aerosol over Dakar (Senegal): impact on dust physico-chemical and radiative properties, Tellus B, 63, 619-634, doi:10.1111/j.16000889.2011.00547.x, 2011.

Preißler, J., Wagner, F., Guerrero-Rascado, J. L., and Silva, A. M.: Two years of free-tropospheric aerosol layers observed over Portugal by lidar, J. Geophys. Res. Atmos., 118, 3676-3686, doi:10.1002/jgrd.50350, 2013.

Rodgers, C. D.: Inverse Methods for Atmospheric Sounding: Theory and Practice, Series on Atmospheric, Oceanic and Planetary Physics, 2, edited by: Taylor, F. W., World Scientific, New Jersey, 2000.

Rogers, R. R., Hair, J. W., Hostetler, C. A., Ferrare, R. A., Obland, M. D., Cook, A. L., Harper, D. B., Burton, S. P., Shinozuka, Y., McNaughton, C. S., Clarke, A. D., Redemann, J., Russell, P. B., Livingston, J. M., and Kleinman, L. I.: NASA LaRC airborne high spectral resolution lidar aerosol measurements during MILAGRO: observations and validation, Atmos. Chem. Phys., 9, 4811-4826, doi:10.5194/acp-9-4811-2009, 2009.

Russell, P. B., Kacenelenbogen, M., Livingston, J. M., Hasekamp, O. P., Burton, S. P., Schuster, G. L., Johnson, M. S., Knobelspiesse, K. D., Redemann, J., Ramachandran, S., and Holben, B.: A Multi-parameter aerosol classificatin method and its application to retrievals from spaceborne polarimetry, J. Geophys. Res., submitted, 2014.

Schuster, G. L., Vaughan, M., MacDonnell, D., Su, W., Winker, D., Dubovik, O., Lapyonok, T., and Trepte, C.: Comparison of CALIPSO aerosol optical depth retrievals to AERONET measurements, and a climatology for the lidar ratio of dust, Atmos. Chem. Phys., 12, 7431-7452, doi:10.5194/acp-12-7431-2012, 2012.

Shindell, D. T., Lamarque, J. F., Schulz, M., Flanner, M., Jiao, C., Chin, M., Young, P., Lee, Y. H., Rotstayn, L., Milly, G., Faluvegi, G., Balkanski, Y., Collins, W. J., Conley, A. J., Dalsoren, S., Easter, R., Ghan, S., Horowitz, L., Liu, X., Myhre, G., Nagashima, T., Naik, V., Rumbold, S., Skeie, R., Sudo, K., Szopa, S., Takemura, T., Voulgarakis, A., and Yoon, J. H.: Radiative forcing in the ACCMIP historical and future climate simulations, Atmos. Chem. Phys. Discuss., 12, 21105-21210, doi:10.5194/acpd-12-21105-2012, 2012.

Su, W. Y., Schuster, G. L., Loeb, N. G., Rogers, R. R., Ferrare, R. A., Hostetler, C. A., Hair, J. W., and Obland, M. D.: Aerosol and cloud interaction observed from high spectral resolution lidar data, J. Geophys. Res.-Atmos., 113, D24202, doi:10.1029/2008jd010588, 2008.

Sugimoto, N. and Lee, C. H.: Characteristics of dust aerosols inferred from lidar depolarization measurements at two wavelengths, Appl. Optics, 45, 7468-7474, 2006.
Sugimoto, N., Uno, I., Nishikawa, M., Shimizu, A., Matsui, I., Dong, X., Chen, Y., and Quan, H.: Record heavy Asian dust in Beijing in 2002: Observations and model analysis of recent events, Geophys. Res. Lett., 30, 1640, doi:10.1029/2002g1016349, 2003.

Tesche, M., Ansmann, A., Müller, D., Althausen, D., Engelmann, R., Freudenthaler, V., and Groß, S.: Vertically resolved separation of dust and smoke over Cape Verde using multiwavelength Raman and polarization lidars during Saharan Mineral Dust Experiment 2008, J. Geophys. Res., 114, D13202, doi:10.1029/2009jd011862, 2009.

Tesche, M., Müller, D., Groß, S., Ansmann, A., Althausen, D., Freudenthaler, V., Weinzierl, B., Veira, A., and Petzold, A.: Optical and microphysical properties of smoke over Cape Verde inferred from multiwavelength lidar measurements, Tellus B, 63, 677-694, doi:10.1111/j.1600-0889.2011.00549.x, 2011.

Textor, C., Schulz, M., Guibert, S., Kinne, S., Balkanski, Y., Bauer, S., Berntsen, T., Berglen, T., Boucher, O., Chin, M., Dentener, F., Diehl, T., Easter, R., Feichter, H., Fillmore, D., Ghan, S., Ginoux, P., Gong, S., Grini, A., Hendricks, J., Horowitz, L., Huang, P., Isaksen, I., Iversen, I., Kloster, S., Koch, D., Kirkevåg, A., Kristjansson, J. E., Krol, M., Lauer, A., Lamarque, J. F., Liu, X., Montanaro, V., Myhre, G., Penner, J., Pitari, G., Reddy, S., Seland, Ø., Stier, P., Takemura, T., and Tie, X.: Analysis and quantification of the diversities of aerosol life cycles within AeroCom, Atmos. Chem. Phys., 6, 1777-1813, doi:10.5194/acp-6-1777-2006, 2006.

Textor, C., Schulz, M., Guibert, S., Kinne, S., Balkanski, Y., Bauer, S., Berntsen, T., Berglen, T., Boucher, O., Chin, M., Dentener, F., Diehl, T., Feichter, J., Fillmore, D., Ginoux, P., Gong, S., Grini, A., Hendricks, J., Horowitz, L., Huang, P., Isaksen, I. S. A., Iversen, T., Kloster, S., Koch, D., Kirkevåg, A., Kristjansson, J. E., Krol, M., Lauer, A., Lamarque, J. F., Liu, X., Montanaro, V., Myhre, G., Penner, J. E., Pitari, G., Reddy, M. S., Seland, Ø., Stier, P., Takemura, T., and Tie, X.: The effect of harmonized emissions on aerosol properties in global models an AeroCom experiment, Atmos. Chem. Phys., 7, 4489-4501, doi:10.5194/acp-7-4489-2007, 2007.

Veselovskii, I., Whiteman, D. N., Korenskiy, M., Kolgotin, A., Dubovik, O., and Perez-Ramirez, D.: Retrieval of heighttemporal distributions of particle parameters from multiwavelength lidar measurements using linear estimation technique and comparison results with AERONET, Atmos. Meas. Tech. Discuss., 6, 3059-3088, doi:10.5194/amtd-6-3059-2013, 2013.

Weinzierl, B., Sauer, D., Esselborn, M., Petzold, A., Veira, A., Rose, M., Mund, S., Wirth, M., Ansmann, A., Tesche, M., Gross, S., and Freudenthaler, V.: Microphysical and optical properties of dust and tropical biomass burning aerosol layers in the Cape Verde region - an overview of the airborne in situ and lidar measurements during SAMUM-2, Tellus B, 63, 589-618, doi:10.1111/j.1600-0889.2011.00566.x, 2011. 